Review Article

\title{
Recent Advances in Nanoparticles Enhanced Oil Recovery: Rheology, Interfacial Tension, Oil Recovery, and Wettability Alteration
}

\author{
Muhammad Shahzad Kamal, ${ }^{1}$ Ahmad A. Adewunmi, ${ }^{1}$ Abdullah S. Sultan,,2 \\ Mohammed F. Al-Hamad, ${ }^{2,3}$ and Umer Mehmood ${ }^{4}$ \\ ${ }^{1}$ Center for Integrative Petroleum Research, King Fahd University of Petroleum \& Minerals (KFUPM), Dhahran 31261, Saudi Arabia \\ ${ }^{2}$ Department of Petroleum Engineering, King Fahd University of Petroleum \& Minerals (KFUPM), Dhahran 31261, Saudi Arabia \\ ${ }^{3}$ Schlumberger Dhahran Carbonate Research Center, Dhahran, Saudi Arabia \\ ${ }^{4}$ Center of Research Excellence in Renewable Energy, King Fahd University of Petroleum \& Minerals (KFUPM), \\ Dhahran 31261, Saudi Arabia
}

Correspondence should be addressed to Abdullah S. Sultan; sultanas@kfupm.edu.sa

Received 14 June 2017; Accepted 10 August 2017; Published 8 October 2017

Academic Editor: Minea A. Adriana

Copyright (C) 2017 Muhammad Shahzad Kamal et al. This is an open access article distributed under the Creative Commons Attribution License, which permits unrestricted use, distribution, and reproduction in any medium, provided the original work is properly cited.

\begin{abstract}
Chemically enhanced oil recovery methods are utilized to increase the oil recovery by improving the mobility ratio, altering the wettability, and/or lowering the interfacial tension between water and oil. Surfactants and polymers have been used for this purpose for the last few decades. Recently, nanoparticles have attracted the attention due to their unique properties. A large number of nanoparticles have been investigated for enhanced oil recovery applications either alone or in combination with surfactants and/or polymers. This review discusses the various types of nanoparticles that have been utilized in enhanced oil recovery. The review highlights the impact of nanoparticles on wettability alteration, interfacial tension, and rheology. The review also covers the factors affecting the oil recovery using nanoparticles and current challenges in field implementation.
\end{abstract}

\section{Introduction}

It is expected that worldwide energy demand will increase up to $50 \%$ by the end of 2030 [1]. The contribution of renewable resources seems to be insignificant in meeting the increased demand for energy. Therefore, oil will remain the major source of energy in the next few decades. Owing to increased energy demand, it is extremely important to explore the new fields and maximize the production from existing oil fields. However, only one-third of the total oil present in the reservoir can be recovered using conventional oil recovery techniques [2,3]. Several chemicals and thermal and gas injection methods are employed to recover the remaining oil. These are termed as tertiary oil recovery or enhanced oil recovery (EOR) [4-9].

In chemical EOR, better recovery is achieved by injecting certain chemicals. These chemicals are injected to improve the mobility ratio, to reduce interfacial tension (IFT), and/or to alter the wettability of the rock [10-18]. Mobility ratio is a ratio of displacing phase (water) mobility to displaced phase (oil) mobility. A mobility ratio of less than one is achieved using water-soluble polymers [19-24]. Most of the oil is trapped due to high capillary forces and the governing capillary pressure is influenced by rock wettability and oil/water IFT [25]. Surfactants are frequently used to lower the IFT and to alter the wettability [26-32].

The use of nanotechnology has shown potential to solve different problems in oil and gas industry [33-36]. Nanoparticles (NPs) have been utilized in subsurface applications due to their ability to alter certain properties in the formation [37]. NPs exhibit exceptional properties owing to the small size and large surface area [38]. The dispersion of the NPs in the solution depends on the functionality of the NPs. Therefore, NPs are usually treated to avoid interparticles interactions. 
TABLE 1: Properties evaluation of nanoparticles for EOR.

\begin{tabular}{lcc}
\hline Property & Nanoparticles & Ref. \\
\hline \multirow{4}{*}{ Rheology } & $\mathrm{Al}_{2} \mathrm{O}_{3}$ & {$[40,41]$} \\
& $\mathrm{SiO}_{2}$ & {$[41-46]$} \\
& $\mathrm{TiO}_{2}$ & {$[41]$} \\
& $\mathrm{Nanoclay}$ & {$[45,47,48]$} \\
& Polysilicon & {$[49,50]$} \\
& $\mathrm{SiO}_{2}$ & {$[39,40,42,51-53]$} \\
Wettability alterations & $\mathrm{MWCNT}^{\mathrm{a}}-\mathrm{SiO}_{2}$ & {$[37]$} \\
& $\mathrm{Al}_{2} \mathrm{O}_{3}$ & {$[2]$} \\
& $\mathrm{TiO}_{2}$ & {$[41]$} \\
& $\mathrm{Fe}_{2} \mathrm{O}_{3}$ & {$[2]$} \\
$\mathrm{SiO}_{2}$ & {$[35,42,52,54,55]$} \\
IFT & $\mathrm{ZrO}_{2}$ & {$[56]$} \\
& $\mathrm{MWNT} \mathrm{SiO}_{2}$ & {$[37]$} \\
$\mathrm{Al}_{2} \mathrm{O}_{3}$ & {$[2]$} \\
$\mathrm{Al}_{2} \mathrm{O}_{3}$ & {$[2]$} \\
$\mathrm{TiO}_{2}$ & {$[41,57,58]$} \\
$\mathrm{SiO}_{2}$ & {$[39,43,51,52,59-63]$} \\
& $\mathrm{Ni}_{2} \mathrm{O}_{3}$ & {$[40]$} \\
$\mathrm{Al}_{2} \mathrm{O}_{3}$ & {$[41]$} \\
$\mathrm{Fe}_{2} \mathrm{O}_{3}$ & {$[62]$} \\
$\mathrm{SnO}$ & {$[40]$} \\
\hline
\end{tabular}

${ }^{\mathrm{a}} \mathrm{MWCNT}=$ multiwalled carbon nanotubes.

Owing to their small size (1-100 nm), NPs can be propagated through the formation using a stable aqueous dispersion.

EOR chemicals are evaluated mainly using rheology, interfacial tension, wettability alteration, and core flooding experiments. The research on applications of NPs in EOR focused on how these NPs influence the above-mentioned properties and oil recovery.

Table 1 shows the nanoparticles that have been evaluated for EOR. Some reviews also summarized the different aspects of NPs research in EOR. Shamsijazeyi et al. focused on the polymer coated NPs for EOR [1]. Cheraghian and Hendraningrat focused only on the effect of NPs on the flooding experiments [64]. Subsequent sections in this review discuss how various NPs influence rheology, interfacial tension, wettability, and oil recovery.

\section{Interfacial Tension}

The surface free energy that exists between two immiscible liquids is called interfacial tension [67]. Oil recovery is directly related to a dimensionless capillary number $\left(N_{\mathrm{ca}}\right)$, which is defined as a ratio of viscous forces to capillary forces. Mathematically, it can be represented by

$$
N_{\mathrm{ca}}=\frac{\text { Viscous forces }}{\text { Capillary forces }}=\frac{\nu \mu}{\sigma \cos \theta},
$$

where $v$ is the velocity, $\mu$ is the dynamic viscosity, $\sigma$ is oilwater IFT, and $\theta$ is the contact angle. A higher capillary number is essential in order to reduce residual oil saturation significantly. To obtain such a higher capillary number, IFT must be decreased to an ultra-low value $\left(10^{-3} \mathrm{mN} / \mathrm{m}\right)[68-$ 73]. Historically, surfactants have been used to lower the IFT and to achieve a higher capillary number [73-82].

NPs can have a strong effect on the interfacial tension. Silicon oxide NPs have been extensively used in EOR [83]. Lan et al. investigated the synergistic effect of silicon oxide NPs and cationic surfactant on the IFT [35]. The cationic surfactant can alter the surface of the NPs from fully hydrophilic to partially hydrophobic, which promotes the aggregation of NPs resulting in lowering the IFT. Ma et al. investigated the effect of silicon oxide NPs on the IFT behavior of the anionic surfactant and they found that addition of hydrophilic silicon oxide NPs enhances the efficacy of anionic surfactant in reducing the IFT [55]. However, hydrophilic silicon oxide particles have no influence on the performance of nonionic surfactant. Moradi et al. found that silica NPs reduce the IFT between oil and water as they are located at oil/water interface [42]. A study conducted by Ershadi et al. revealed that multiwalled carbon nanotubes- (MWCNT-) silicon oxide hybrid NPs could reduce the kerosene-water IFT from $53.9 \mathrm{mN} / \mathrm{m}$ to $27.5 \mathrm{mN} / \mathrm{m}$. However, the decrease is not significant in terms of EOR application [37].

Esmaeilzadeh et al. studied the impact of $\mathrm{ZrO}_{2}$ on interfacial properties of anionic surfactant. They found that NPs augment the surface activity of the anionic surfactant and lower the IFT between water and oil [56]. Joonaki and Ghanaatian investigated the effect of aluminum oxide, iron oxide, and silicon oxide on the IFT and found that increasing the concentration of NPs reduced the IFT. Silicon oxide was more efficient in reducing the interfacial tension between water and oil [2]. Zargartalebi et al. investigated the effect of fumed silicon oxide NPs on the efficiency of surfactant in reducing the interfacial tension [83].

The concentration of NPs and surfactant is the most important parameter affecting the IFT. Zargartalebi et al. used partially hydrophobic silicon oxide and fumed silicon oxide to investigate the effect on IFT in the presence of surfactant [54]. They observed that, at lower surfactant concentrations, added NPs reduce the IFT. However, at higher concentrations, IFT increased due to the addition of NPs. It can be attributed to the electrostatic repulsive interactions between NPs and the anionic surfactant that promotes the diffusion of the surfactant towards the interface [55]. In addition, NPs can act as carriers of surfactant molecules towards the interface. However, at high concentrations, NPs attract the surfactants molecules that can lead towards the aggregation of surfactant molecules. Similar results were reported for $\mathrm{ZrO}_{2}$ (Table 2, Entries (15)-(17)) NPs by Esmaeilzadeh et al. [56]. Sun et al. used $\mathrm{SiO}_{2}$ in the presence of surfactant (Table 2, Entries (6)-(10)) and found that IFT slightly increased by increasing the NPs concentrations [3]. However, the IFT with NPs was always higher compared to a solution without NPs. This is due to the fact that they used comparatively high concentration of NPs ( $2 \mathrm{wt} \%)$ and ignored lower concentrations where IFT increase was expected.

NPs can lower the adsorption of surfactant on the reservoir rock in addition to lowering IFT [83]. Zargartalebi et al. found that silicon oxide NPs can reduce the adsorption of anionic surfactant (sodium dodecyl sulfate) on sandstone 
TABLE 2: IFT data of different nanofluids.

\begin{tabular}{|c|c|c|c|c|c|c|c|}
\hline Entry\# & NPs & $\begin{array}{l}\text { NPs conc. } \\
\quad(\mathrm{wt} \%)\end{array}$ & $\begin{array}{l}\text { Dispersion } \\
\text { media }\end{array}$ & $\begin{array}{c}\text { Surfactant } \\
\text { conc. } \\
\text { (wt } \%)\end{array}$ & $\begin{array}{l}\text { IFT without NPs } \\
(\mathrm{mN} / \mathrm{m})\end{array}$ & $\begin{array}{l}\text { IFT with NPs } \\
(\mathrm{mN} / \mathrm{m})\end{array}$ & Ref. \\
\hline (1) & $\mathrm{SiO}_{2}$ & 0.3 & Propanol & 0 & 38.5 & 1.45 & [2] \\
\hline (2) & $\mathrm{SiO}_{2}$ & 0.1 & Water & 0 & 13.62 & 10.69 & [42] \\
\hline (3) & $\mathrm{SiO}_{2}$ & 0.1 & Ethanol & 0 & 25 & 5 & [52] \\
\hline (4) & $\mathrm{SiO}_{2}$ & 0.05 & Brine & 0 & 19.2 & 16.9 & [65] \\
\hline (5) & $\mathrm{SiO}_{2}$ & 0 & Brine & 0.5 & 21.7 & 4.2 & [3] \\
\hline (6) & $\mathrm{SiO}_{2}$ & 0.1 & Brine & 0.5 & 21.7 & 4.5 & [3] \\
\hline (7) & $\mathrm{SiO}_{2}$ & 0.5 & Brine & 0.5 & 21.7 & 5.2 & [3] \\
\hline (8) & $\mathrm{SiO}_{2}$ & 1.0 & Brine & 0.5 & 21.7 & 5.8 & [3] \\
\hline (9) & $\mathrm{SiO}_{2}$ & 1.5 & Brine & 0.5 & 21.7 & 6.1 & [3] \\
\hline (10) & $\mathrm{SiO}_{2}$ & 2.0 & Brine & 0.5 & 21.7 & 6.3 & [3] \\
\hline (11) & $\mathrm{Al}_{2} \mathrm{O}_{3}$ & 0.3 & Propanol & 0 & 38.5 & 2.25 & [2] \\
\hline (12) & $\mathrm{Fe}_{2} \mathrm{O}_{3}$ & 0.3 & Propanol & 0 & 38.5 & 2.75 & [2] \\
\hline (13) & $\mathrm{ZrO}_{2}$ & 0.01 & Water & 0.2 & 16 & 3.1 & [66] \\
\hline (14) & $\mathrm{ZrO}_{2}$ & 0.01 & Water & 0.3 & 18.4 & 5.4 & [66] \\
\hline (15) & $\mathrm{ZrO}_{2}$ & 0.001 & Water & 0 & 51.4 & 37.2 & [56] \\
\hline (16) & $\mathrm{ZrO}_{2}$ & 0.01 & Water & 0 & 51.4 & 37.2 & [56] \\
\hline$(17)$ & $\mathrm{ZrO}_{2}$ & 0.1 & Water & 0 & 51.4 & 36.8 & [56] \\
\hline
\end{tabular}

rock surface [54]. The decrease in adsorption becomes significant by increasing the hydrophobicity of the NPs. The adsorption of the surfactant in the presence of NPs was investigated in two different scenarios. In the first case, a NPs-augmented surfactant solution was put in contact with rock samples. It was observed that adsorption of the surfactant decreased up to critical micelle concentration (CMC) when compared to surfactant solution without NPs. At higher concentrations, adsorption of the surfactant was higher. In the second case, rock samples were equilibrated with surfactant-NPs suspension for 24 hours. The adsorption of the surfactant decreased at lower concentrations but increased at higher concentrations. The equilibrium adsorption was higher compared to the previous case when NPsaugmented NPs solution was used.

In summary, NPs help in reducing the IFT either alone or in combination with surfactants. Moreover, NPs can also reduce the adsorption of surfactants on reservoir rock surface. However, additional experimental work is required to understand the underlying mechanism of improvement in interfacial properties using NPs. Mainly, experimental studies that have been carried out in this field dealt with determining the optimum NPs concentrations corresponding to minimum IFT. However, there is a lack of information on surfactant-NPs interactions. In addition, there is limited data on the interfacial behavior of surfactants with NPs other than silica. There is a huge potential for further investigation in this area, for example, how interfacial properties are altered if oil is changed from light to heavy or surfactants are changed from cationic to nonionic, zwitterionic or anionic, and so on.

\section{Wettability Alteration}

Wettability is defined as the affinity of solid surface for a particular liquid to occupy the pore space in the presence of other immiscible liquids $[67,84]$. Wettability is a key parameter that controls the location and distribution of fluids in the formation [85]. Based on wettability, oil reservoirs can be characterized as water-wet, oil-wet, or mixed-wet. It is well established that oil recovery from water-wet reservoirs is high and recovery rate becomes lower as rock becomes more oilwet [86]. However, the most carbonate reservoirs are oil-wet to mixed-wet [84]. Therefore, in the petroleum industry, the term wettability alteration means changing the wettability of reservoir rock from oil-wet to more water-wet [86]. Wettability alteration of any solid surface can be determined using spontaneous imbibition, contact angle measurements, zeta potential measurements, and surface imaging tests. Atomic force microscopy, scanning electron microscopy, and nuclear magnetic resonance spectroscopy can provide changes in the rock properties because of wettability alteration. Surfactants have been investigated in detail for wettability alteration [87-91]. Many researchers reported results on the wettability alteration using NPs either alone or in combination with the surfactant. The wettability alteration using NPs depends on several factors such as nature of NPs, hydrophobicity, nature of reservoir, and concentration of NPs. Contact angle data of various NPs is shown in Table 3.

Nature of nanoparticles has a crucial role in changing the wettability of the rock. Silicon oxide NPs dispersed in ethanol has been reported to alter the rock wettability. Lipophilic polysilicon nanoparticles change the wettability of rock from 
TABLE 3: Contact angle data of different NPs.

\begin{tabular}{lcccccc}
\hline Entry\# & $\mathrm{NPs}$ & $T\left({ }^{\circ} \mathrm{C}\right)$ & Dispersion media & Contact angle of clean rock & Contact angle after treatment & Ref. \\
\hline$(1)$ & $\mathrm{SiO}_{2}$ & 25 & Propanol & 134 & 82 & {$[2]$} \\
$(2)$ & $\mathrm{SiO}_{2}$ & $\mathrm{~A}^{\mathrm{a}}$ & Water & 122 & 24 & {$[42]$} \\
$(3)$ & $\mathrm{SiO}_{2}$ & 23 & Ethanol & 135.5 & 66 & {$[52]$} \\
$(4)$ & $\mathrm{SiO}_{2}$ & 26 & $\mathrm{H}_{2} \mathrm{O}$ & 90 & 26 & {$[41]$} \\
$(5)$ & $\mathrm{SiO}_{2}$ & 40 & $\mathrm{H}_{2} \mathrm{O}$ & 87 & 25 & {$[41]$} \\
$(6)$ & $\mathrm{SiO}_{2}$ & 50 & $\mathrm{H}_{2} \mathrm{O}$ & 83 & 21 & {$[41]$} \\
$(7)$ & $\mathrm{SiO}_{2}$ & 60 & $\mathrm{H}_{2} \mathrm{O}$ & 82 & 18 & {$[41]$} \\
$(8)$ & $\mathrm{Al}_{2} \mathrm{O}_{3}$ & 25 & $\mathrm{Propanol}$ & 134 & 90 & {$[2]$} \\
$(9)$ & $\mathrm{Al}_{2} \mathrm{O}_{3}$ & 26 & $\mathrm{H}_{2} \mathrm{O}$ & 90 & 71 & {$[41]$} \\
$(10)$ & $\mathrm{Al}_{2} \mathrm{O}_{3}$ & 40 & $\mathrm{H}_{2} \mathrm{O}$ & 87 & 66 & {$[41]$} \\
$(11)$ & $\mathrm{Al}_{2} \mathrm{O}_{3}$ & 50 & $\mathrm{H}_{2} \mathrm{O}$ & 83 & 65 & {$[41]$} \\
$(12)$ & $\mathrm{Al}_{2} \mathrm{O}_{3}$ & 60 & $\mathrm{H}_{2} \mathrm{O}$ & 82 & 61 & {$[41]$} \\
$(13)$ & $\mathrm{Fe}_{2} \mathrm{O}_{3}$ & 25 & $\mathrm{Propanol}$ & 134 & 98 & {$[2]$} \\
$(14)$ & $\mathrm{TiO}_{2}$ & 26 & $\mathrm{H}_{2} \mathrm{O}$ & 90 & 57 & {$[41]$} \\
$(15)$ & $\mathrm{TiO}_{2}$ & 40 & $\mathrm{H}_{2} \mathrm{O}$ & 87 & 52 & {$[41]$} \\
$(16)$ & $\mathrm{TiO}_{2}$ & 50 & $\mathrm{H}_{2} \mathrm{O}$ & 83 & 49 & {$[41]$} \\
$(17)$ & $\mathrm{TiO}_{2}$ & 60 & $\mathrm{H}_{2} \mathrm{O}$ & 82 & 46 & {$[41]$} \\
\hline
\end{tabular}

${ }^{\mathrm{a}} \mathrm{A}=$ ambient temperature.

oil-wet to water-wet. In addition, they can strengthen the wettability of water-wet rock to more water-wet rock [50]. Hydrophobic polysilicon nanoparticles change the wettability of rock from water-wet to oil-wet and change an already oilwet rock to strongly oil-wet rock. Neutrally wet polysilicon NPs change the wettability of the rock to an intermediatewet state due to the presence of hydrophobic and hydrophilic moieties. Hydrophilic polysilicon should be restricted to oil-wet formations while hydrophobic polysilicon should be restricted to a water-wet formation, because hydrophilic polysilicon changes a water-wet formation to more water-wet and hinders oil production which results in poor oil recovery [50]. Similarly, polysilicon NPs treated with silane can change the wettability of the rock and have shown good results in water-wet formations [52].

Ju et al. theoretically studied the wettability alteration of rock using polysilicon NPs [49]. They found that hydrophilic polysilicon NPs adsorb on pore walls and alter the sandstone rock wettability. Maghzi et al. used five-spot glass micromodel to study wettability alteration with silicon oxide NPs [39]. They concluded that a strong hydrogen bond between silicon oxide NPs and water exists and increased surface free energy changed the wettability of the rock from oil-wet to water-wet. In addition, it was observed that adsorption of the silicon oxide NPs on the surface is a necessary condition of wettability alteration.

Maghzi et al. investigated the effects of $\mathrm{SiO}_{2} \mathrm{NPs}$ on fluid distribution on the walls of pores/throats and microscopic pictures revealed the distribution of oil, water, and $\mathrm{SiO}_{2} \mathrm{NPs}$. Figure 1 displays the fluids distribution during water flooding test. They also observed that oil remains on the wall of the pores while water is trapped inside the pores due to the oilwet property of the medium. In contrast, Figure 2 highlights the picture of microscopic fluids distribution observed during $\mathrm{SiO}_{2}$ NPs flooding at different concentrations. They noticed that the ability of $\mathrm{SiO}_{2}$ NPs to alter wettability of pores surfaces was obvious, especially at higher percentages of $\mathrm{SiO}_{2}$ NPs. In this way, the flow of $\mathrm{SiO}_{2}$ in the medium to remove oil from the walls of pores resulted in an increased oil recovery [39].

Some other factors are also important in wettability alteration using NPs such as nature of oil, concentrations of NPs, and type of NPs. Roustaei et al. studied the effect of modified silicon oxide NPs on light and heavy oil recovery. They found that $\mathrm{SiO}_{2}$ NPs are more effective in wettability alteration of light oil reservoir [52]. Roustaei and Bagherzadeh studied the impact of silica NPs on the change in wettability of carbonate rock [51]. They determined that an optimum concentration is required in order to achieve the wettability alteration. In addition, silica NPs effectively modify the wettability of a carbonate rock from oil-wet to water-wet. Joonaki and Ghanaatian used $\mathrm{Al}_{2} \mathrm{O}_{3}, \mathrm{SiO}_{2}$ and $\mathrm{Fe}_{2} \mathrm{O}_{3}$ NPs using propanol as a dispersing agent to investigate wettability alteration of sandstone rocks [2]. They found that $\mathrm{SiO}_{2} \mathrm{NPs}$ are more efficient in altering the wettability of the rock. Moradi et al. found that silicon oxide NPs alter the wettability of carbonate rock by adsorbing on the surface [42]. Ershadi et al. used multiwalled carbon nanotubes- (MWCNT-) silicon oxide nanofluid for the wettability alteration of different rock samples [37].

In summary, hydrophilic NPs should be preferred in the case of oil-wet formations while hydrophobic NPs should be used in water-wet formation. The optimum concentration of NPs is required in order to achieve the desired wettability. Most of the literature on wettability alteration using NPs is on sandstone systems; however, the literature on wettability 


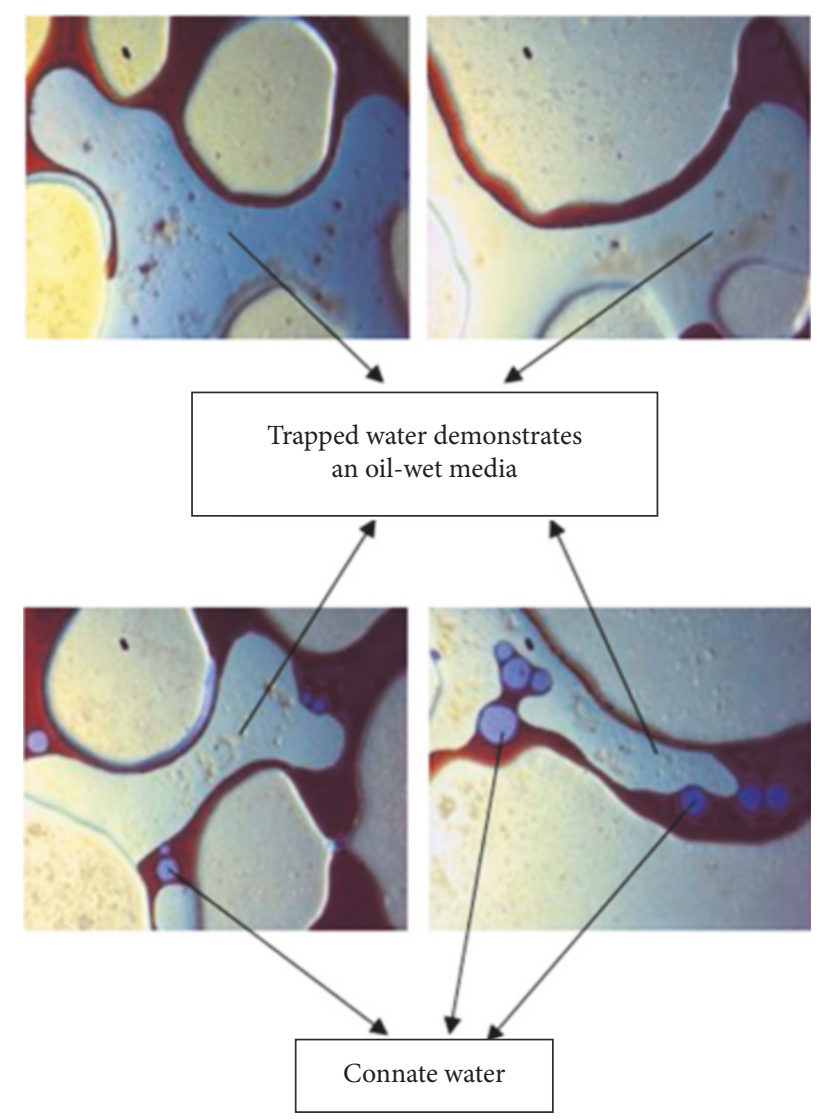

FIgURE 1: Pore-scale investigation of wettability (water injection) [39]. (CElsevier. Reproduced with the permission of the publisher.

alteration of carbonate rocks is limited. Considering the vital importance of carbonate reservoirs, it is necessary to understand the NPs-carbonate interactions by varying different factors such as size and type of NPs, NPs preparation methods, stability, salinity, rock type, and geological conditions. Only a few publications reported the porescale investigation of wettability alteration and need further investigation [39]. Though considerable work has already been started on carbonate rocks, the fundamentals are not completely understood yet.

\section{Rheology}

Rheological measurements play an important role in the assessment of the viscoelastic nature of fluids and polymeric materials. Understanding of the flow behavior and dynamics of constituent particles in the suspension of nanocolloids is crucial for characterizing the structure and properties of nanofluids (NFs). Particle migration and transport in NFs have a significant effect on the rheological behavior of the suspension and, therefore, have a great implication on the future utilization of NFs. Thus, a good understanding of rheological properties of NFs for EOR purposes is of great interest in the petroleum industry. Rheological measurements are fundamental in designing and determining the

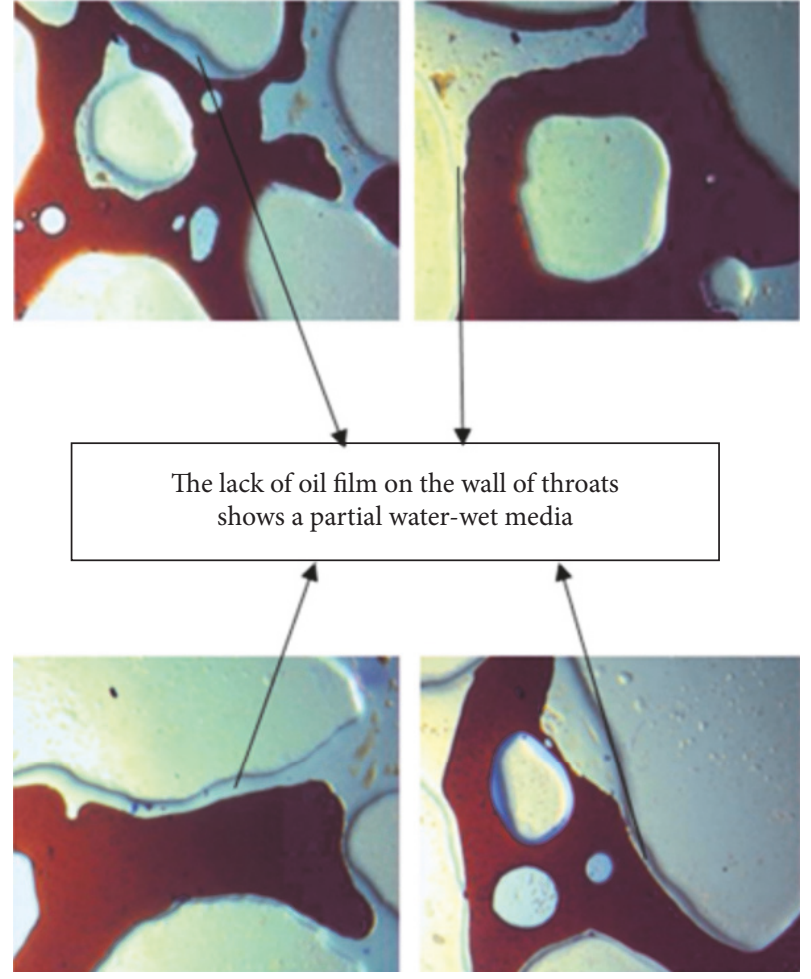

FIGURE 2: Pore-scale investigation of wettability (NPs injection) [39]. CElsevier. Reproduced with the permission of the publisher.

optimum concentrations of the injection fluids for EOR applications. Mathematically, mobility ratio is presented as $k_{\mathrm{w}} \mu_{\mathrm{o}} / k_{\mathrm{o}} \mu_{\mathrm{w}}$, where $\mu$ and $k$ are viscosity and permeability, respectively. Subscript $\mathrm{w}$ is for displacing phase (water) and $\mathrm{o}$ is for displaced phase (oil). Mobility ratio of less than one is favorable to avoid viscous fingering. In the case of higher mobility ratio, viscous fingering occurs due to the higher mobility of water. Rheology is an important technique to determine the viscosity of the injection fluids. Only a few scientific research articles describe the rheological properties of NFs for EOR processes.

The use of NFs to mitigate the adverse effect caused by salinity has been of great interest during EOR processes. Cheraghian et al. developed nanoclay/polyacrylamide (PAM) systems with different concentrations of clays for an optimum viscous solution at $25^{\circ} \mathrm{C}$ and $80^{\circ} \mathrm{C}$. They investigated the utilization of nanoclay to reduce the negative impacts caused by salinity on PAM fluids in EOR processes. The result showed that certain range of nanoclay content had a positive impact on the PAM viscosity [47]. It is evident from their results that NFs perform favorably within a certain range of nanoclay addition.

A great effort is being intensified by researchers to study the effect of different NPs on the rheological characteristics of NFs for EOR purposes. Bayat and coworkers investigated the influence of $\mathrm{SiO}_{2}, \mathrm{Al}_{2} \mathrm{O}_{3}$, and $\mathrm{TiO}_{2}$ containing NFs on the viscosity behavior of oil produced after each NPs flooding experiment. They observed that the viscosity of oils produced 
after NFs flooding changed. The rate of these changes was reported to be low at $26^{\circ} \mathrm{C}$, while they became considerable at higher temperatures. $\mathrm{Al}_{2} \mathrm{O}_{3}$ and $\mathrm{SiO}_{2}$ containing NFs were observed to have caused the highest and lowest amount of viscosity reduction at all temperatures $\left(26^{\circ} \mathrm{C}\right.$ to $\left.60^{\circ} \mathrm{C}\right)$ [41]. In an investigation by Maghzi et al., the rheological behavior of $\mathrm{SiO}_{2}$ nanosuspension in PAM solution revealed that the viscosity of $\mathrm{SiO}_{2}$ nanosuspension in PAM was higher than that of PAM solution at the same salinity. According to their report, the increase in viscosity became noticeable when $\mathrm{SiO}_{2}$ NPs concentration was increased [43]. In addition, Pei et al. reported the effect of $\mathrm{SiO}_{2}$ NPs content on the rheology of oil-in-water $(\mathrm{o} / \mathrm{w})$ emulsions. They noticed that viscosities of $\mathrm{o} / \mathrm{w}$ emulsions enhanced when the concentration was increased. Furthermore, they observed that the viscosity of the emulsion decreased by increasing the shear rate [44]. The experimental results of these researchers demonstrated that the rheological behavior of NFs depends greatly on the type of NPs employed to develop the NFs and on the experimental conditions.

Further, the experimental parameters like temperature and pressure have significant impacts on the viscoelastic behavior of NFs. Very few studies have buttressed the effect of high pressure high temperature (HPHT) conditions on NFs used for EOR. In a study conducted by Sharma et al., the viscosity behavior of Pickering emulsion using NPs of $\mathrm{SiO}_{2}$ ( $1 \mathrm{wt} \%$ ) and clay (1 wt\%) with surfactant-polymer (SP) system for EOR was evaluated [48]. The increase in temperature reduced the viscosity of the SP system. However, there were no significant changes in the viscosity of the Pickering emulsion with the increase in temperature. Another similar study by Sharma and Sangwai reported the effect of $\mathrm{NaCl}$ on the rheological properties of Pickering emulsion stabilized by silica/clay nanoparticles-SP system at different pressures and temperature $\left(25\right.$ to $\left.98^{\circ} \mathrm{C}\right)$ [45]. Their findings in the dynamic rheological properties measurements revealed that the addition of salts slightly affected the viscosity of NPsSP emulsions. However, the addition of salt changes the $G^{\prime}$ and $G^{\prime \prime}$ at HPHT conditions. They concluded that NPsSP emulsion system infused with salt is suitable for HPHT applications such as EOR and drilling fluids for high salinity conditions.

In summary, the published articles on the rheological behavior of NFs have shown that the inclusion of NPs has a significant effect on the viscosity, storage, and loss moduli of NFs. The NFs exhibited favorable rheological results than the fluids without NPs. However, these experiments were conducted at temperatures less than $100^{\circ} \mathrm{C}$. There is a pressing need to investigate the rheology of NFs at elevated temperatures (up to $150^{\circ} \mathrm{C}$ ) because some oil reservoirs temperature is above $100^{\circ} \mathrm{C}$. In addition, the rheological behavior of reservoir fluid mixed with NPs should be investigated thoroughly as this gives the best idea of what might occur during life operation in oilfields. The NPs interactions with surfactant and polymer at different reservoir conditions are worth further investigation in order to understand the mechanism. Besides, the impact of NPs inclusion on the thermal stability of water-soluble polymers requires further studies.

\section{Core Flooding}

Core flooding tests are widely used in the petroleum industry to determine the oil recovery at specific reservoir conditions. The cores used during flooding experiments provide the ground truth for manipulating all other sources of formation evaluation information [92]. Core flooding tests are timeconsuming and it is not possible to conduct a large number of core flooding experiments. Therefore, data obtained from initial screening tests using rheology, IFT, and wettability alteration can minimize the number of core flooding experiments. Several core flooding experiments have been performed using an injection of NPs. Table 4 highlights some of the NPs and the recovery factor obtained using NPs injection. Data given in Table 4 shows that NPs can also have a negative impact on the oil recovery. Therefore, it is extremely important to optimize different factors to have a maximum recovery. Following sections will highlight the various factors that affect the oil recovery.

5.1. Concentration. The concentration of NPs is the most important factor in core flooding experiments. Usually, the optimum concentrations are determined using initial screening techniques such as rheology, IFT, and adsorption. Ehtesabi et al. used $\mathrm{TiO}_{2} \mathrm{NPs}$ in core flooding test using sandstone core [57]. They found that using a brine of $5000 \mathrm{ppm}$ recovered $49 \%$ of the oil, while the use of $\mathrm{TiO}_{2}$ NPs $(0.01 \%)$ increased oil recovery factor up to $80 \%$ ( $31 \%$ additional oil recovery). However, the change in the concentration of $\mathrm{TiO}_{2}$ NPs to $1 \%$ did not show any impressive effect on the recovery factor and recovery obtained was lower than what was achieved using brine only. In addition, they conducted core flooding experiments using $1 \mathrm{wt} \% \mathrm{TiO}_{2}$ amorphous NPs. The recovery factor was found to be $23 \%$, which was less than the recovery factor obtained when only brine was used (Table 4, Entries (5)-(7)). SEM coupled with EDS instrument showed that the $\mathrm{TiO}_{2}$ NPs were deposited on the surface of the rock (Figures 3 and 4 ) while the EDS map showed that $\mathrm{TiO}_{2}$ deposited homogeneously onto the stone (Figure 5).

Son et al. evaluated the $\mathrm{SiO}_{2}$ NPs and polyvinyl alcohol (PVA) stabilized emulsion [59]. Emulsion with a low concentration $(0.05 \mathrm{wt} \%)$ of PVA and a high concentration (3 wt\%) of $\mathrm{SiO}_{2} \mathrm{NPs}$ had greater stability and vice versa. Furthermore, the addition of salts ( $1 \mathrm{wt} \%$ ) efficiently stabilized the emulsion droplets without any significant coalescence and contributed to approximately $4 \%$ more oil recovery than what is achieved in the absence of emulsion system.

Maghzi et al. studied the effects of dispersed $\mathrm{SiO}_{2} \mathrm{NPs}$ in water at different concentrations $(0.1 \mathrm{wt} \%$ to $5 \mathrm{wt} \%)$ [39]. The increase in the concentration of NPs increased the oil recovery (Table 4, Entries (14)-(15)). Also, the ultimate efficiency achieved for $\mathrm{SiO}_{2}$ NPs (0.1 wt\%) flooding was higher (8.7\%) compared to distilled water flooding. The increases in concentration from $0.1 \%$ to $0.3 \%$ cause the additional oil recovery to reach up to $26 \%$. However, an optimum concentration of NPs is required to achieve the maximum recovery [39]. 
TABLE 4: Some of the NPs employed in EOR to develop nanofluids.

\begin{tabular}{|c|c|c|c|c|c|c|c|c|}
\hline Entry\# & NPs & Dispersing medium & NPs conc ${ }^{\mathrm{a}}$ & Surfactant conc & Core & Recovery (\%) & $T^{\mathrm{b}}\left({ }^{\circ} \mathrm{C}\right)$ & Ref. \\
\hline (1) & $\mathrm{TiO}_{2}$ & Water & 0.005 & 0 & $\mathrm{C}^{\mathrm{c}}$ & 3.0 & 26 & [41] \\
\hline (2) & $\mathrm{TiO}_{2}$ & Water & 0.005 & 0 & C & 4.1 & 40 & [41] \\
\hline (3) & $\mathrm{TiO}_{2}$ & Water & 0.005 & 0 & $\mathrm{C}$ & 5.2 & 50 & [41] \\
\hline (4) & $\mathrm{TiO}_{2}$ & Water & 0.005 & 0 & $\mathrm{C}$ & 6.6 & 60 & [41] \\
\hline (5) & $\mathrm{TiO}_{2}$ & Water & 0.01 & 0 & $S^{\mathrm{d}}$ & 31 & 75 & [57] \\
\hline (6) & $\mathrm{TiO}_{2}$ anatase & Water & 1 & 0 & S & -7 & 75 & [57] \\
\hline (7) & $\mathrm{TiO}_{2}$ amorphous & Water & 0.01 & 0 & S & -26 & 75 & [57] \\
\hline (8) & $\mathrm{SiO}_{2}{ }^{\mathrm{e}}$ & Brine & 0.05 & 0 & S & 6 & $\mathrm{~A}^{\mathrm{k}}$ & {$[63]$} \\
\hline (9) & $\mathrm{SiO}_{2}{ }^{\mathrm{f}}$ & Brine & 0.05 & 0 & S & 0 & $\mathrm{~A}$ & [63] \\
\hline (10) & $\mathrm{SiO}_{2}{ }^{\mathrm{g}}$ & Brine & 0.05 & 0 & S & 15 & A & [63] \\
\hline (11) & $\mathrm{SiO}_{2}{ }^{\mathrm{h}}$ & Brine & 0.05 & 0 & S & 3 & A & [63] \\
\hline (12) & $\mathrm{SiO}_{2}{ }^{\mathrm{i}}$ & Brine & 0.05 & 0 & S & 3 & A & [63] \\
\hline (13) & $\mathrm{SiO}_{2}{ }^{\mathrm{j}}$ & Brine & 0.05 & 0 & S & 12 & A & [63] \\
\hline (14) & $\mathrm{SiO}_{2}$ & Water & 0.1 & 0 & $\mathrm{~s}$ & 8.7 & A & [39] \\
\hline (15) & $\mathrm{SiO}_{2}$ & Water & 0.3 & 0 & S & 26 & A & [39] \\
\hline (16) & $\mathrm{CaCO}_{3}$ & Alcohol & $0.05 \mathrm{~g}$ & 0 & $\mathrm{C}^{\mathrm{b}}$ & 8.7 & 70 & {$[61]$} \\
\hline (17) & $\mathrm{SiO}_{2}$ & Heptane & $0.3 \mathrm{~g}$ & 0 & $\mathrm{C}$ & 7.7 & 70 & {$[61]$} \\
\hline (18) & $\mathrm{SiO}_{2}$ & Water & 0.005 & 0 & $\mathrm{C}$ & 2.0 & 26 & [41] \\
\hline (19) & $\mathrm{SiO}_{2}$ & Water & 0.005 & 0 & $\mathrm{C}$ & 2.5 & 40 & [41] \\
\hline (20) & $\mathrm{SiO}_{2}$ & Water & 0.005 & 0 & $\mathrm{C}$ & 2.8 & 50 & [41] \\
\hline (21) & $\mathrm{SiO}_{2}$ & Water & 0.005 & 0 & C & 2.9 & 60 & [41] \\
\hline (22) & $\mathrm{SiO}_{2}$ & Propanol & 0.15 & 0 & $S$ & 22.5 & A & {$[2]$} \\
\hline (23) & $\mathrm{SiO}_{2}$ & Brine & 0 & 0.5 & $\mathrm{~s}$ & 12.1 & 60 & [3] \\
\hline (24) & $\mathrm{SiO}_{2}$ & Brine & 0.1 & 0.5 & $\mathrm{~s}$ & 16.3 & 60 & [3] \\
\hline (25) & $\mathrm{SiO}_{2}$ & Brine & 0.5 & 0.5 & $\mathrm{~s}$ & 24.4 & 60 & [3] \\
\hline (26) & $\mathrm{SiO}_{2}$ & Brine & 1.0 & 0.5 & S & 29.3 & 60 & [3] \\
\hline (27) & $\mathrm{SiO}_{2}$ & Brine & 1.5 & 0.5 & $S$ & 37.6 & 60 & {$[3]$} \\
\hline (28) & $\mathrm{SiO}_{2}$ & Brine & 2.0 & 0.5 & S & 38.3 & 60 & [3] \\
\hline (29) & $\mathrm{SiO}_{2}$ & Ethanol & 0.3 & 0 & $S$ & 5 & - & [40] \\
\hline (30) & $\mathrm{SiO}_{2}$ & Brine & 0.3 & 0 & S & 4.2 & - & [40] \\
\hline (31) & $\mathrm{SiO}_{2}$ & Water & 0.3 & 0 & S & 0.8 & - & [40] \\
\hline (32) & $\mathrm{SiO}_{2}$ & Ethanol & 0.3 & 0 & S & 1.7 & - & [40] \\
\hline (33) & $\mathrm{SiO}_{2}$ & Water & 0.2 & 0 & S & 0.75 & $\mathrm{~A}$ & [50] \\
\hline (34) & $\mathrm{SiO}_{2}$ & Ethanol & 0.3 & 0 & $\mathrm{~s}$ & 38.75 & A & [50] \\
\hline (35) & $\mathrm{SiO}_{2}$ & Ethanol & 0.3 & 0 & S & 36.67 & A & [50] \\
\hline (36) & $\mathrm{Al}_{2} \mathrm{O}_{3}$ & Water & 0.005 & 0 & $\mathrm{C}$ & 4.5 & 26 & [41] \\
\hline (37) & $\mathrm{Al}_{2} \mathrm{O}_{3}$ & Water & 0.005 & 0 & C & 5.4 & 40 & [41] \\
\hline (38) & $\mathrm{Al}_{2} \mathrm{O}_{3}$ & Water & 0.005 & 0 & C & 7.0 & 50 & [41] \\
\hline (39) & $\mathrm{Al}_{2} \mathrm{O}_{3}$ & Water & 0.005 & 0 & C & 9.9 & 60 & [41] \\
\hline (40) & $\mathrm{Al}_{2} \mathrm{O}_{3}$ & Ethanol & 0.3 & 0 & S & -0.9 & - & [40] \\
\hline (41) & $\mathrm{Al}_{2} \mathrm{O}_{3}$ & Brine & 0.3 & 0 & S & 5 & - & [40] \\
\hline (42) & $\mathrm{Al}_{2} \mathrm{O}_{3}$ & Water & 0.3 & 0 & S & 12.5 & - & [40] \\
\hline (43) & $\mathrm{Al}_{2} \mathrm{O}_{3}$ & Propanol & 0.15 & 0 & S & 20.2 & $\mathrm{~A}$ & [2] \\
\hline (44) & $\mathrm{MgO}$ & Ethanol & 0.3 & 0 & S & -4.5 & - & [40] \\
\hline (45) & $\mathrm{MgO}$ & Brine & 0.3 & 0 & S & -2.5 & - & [40] \\
\hline (46) & $\mathrm{MgO}$ & Water & 0.3 & 0 & S & 1.7 & - & [40] \\
\hline (47) & $\mathrm{Fe}_{2} \mathrm{O}_{3}$ & Ethanol & 0.3 & 0 & S & -4.2 & - & [40] \\
\hline (48) & $\mathrm{Fe}_{2} \mathrm{O}_{3}$ & Brine & 0.3 & 0 & S & 0 & - & [40] \\
\hline (49) & $\mathrm{Fe}_{2} \mathrm{O}_{3}$ & Water & 0.3 & 0 & S & 9.2 & - & [40] \\
\hline (50) & $\mathrm{Fe}_{2} \mathrm{O}_{3}$ & Propanol & 0.15 & & S & 17.3 & A & [2] \\
\hline (51) & $\mathrm{Ni}_{2} \mathrm{O}_{3}$ & Ethanol & 0.3 & 0 & S & -5.0 & - & [40] \\
\hline
\end{tabular}


TABle 4: Continued.

\begin{tabular}{|c|c|c|c|c|c|c|c|c|}
\hline Entry\# & NPs & Dispersing medium & NPs conc $^{a}$ & Surfactant conc & Core & Recovery (\%) & $T^{\mathrm{b}}\left({ }^{\circ} \mathrm{C}\right)$ & Ref. \\
\hline$(52)$ & $\mathrm{Ni}_{2} \mathrm{O}_{3}$ & Brine & 0.3 & 0 & S & 1.7 & - & [40] \\
\hline (53) & $\mathrm{Ni}_{2} \mathrm{O}_{3}$ & Water & 0.3 & 0 & S & 2.0 & - & [40] \\
\hline (54) & $\mathrm{ZnO}$ & Ethanol & 0.3 & 0 & S & -4.2 & - & [40] \\
\hline (55) & $\mathrm{ZnO}$ & Brine & 0.3 & 0 & S & -4.2 & - & [40] \\
\hline (56) & $\mathrm{ZnO}$ & Water & 0.3 & 0 & S & 3.3 & - & [40] \\
\hline (57) & $\mathrm{ZrO}_{2}$ & Ethanol & 0.3 & 0 & $S$ & -5.0 & - & [40] \\
\hline (58) & $\mathrm{ZrO}_{2}$ & Brine & 0.3 & 0 & S & -3.3 & - & [40] \\
\hline (59) & $\mathrm{ZrO}_{2}$ & Water & 0.3 & 0 & S & 4.2 & - & [40] \\
\hline$(60)$ & $\mathrm{SnO}$ & Ethanol & 0.3 & 0 & S & -13.4 & - & [40] \\
\hline (61) & $\mathrm{SnO}$ & Brine & 0.3 & 0 & S & -3.3 & - & [40] \\
\hline (62) & $\mathrm{SnO}$ & Water & 0.3 & 0 & S & 3.3 & - & [40] \\
\hline
\end{tabular}

${ }^{\mathrm{a}}$ Concentration, ${ }^{\mathrm{b}}$ temperature, ${ }^{\mathrm{c}}$ carbonate core, ${ }^{\mathrm{d}}$ sandstone core, ${ }^{\mathrm{e}-\mathrm{j}}$ the same $\mathrm{SiO}_{2}$ concentration but different SW composition during preparation, and $\mathrm{k}$ ambient conditions.

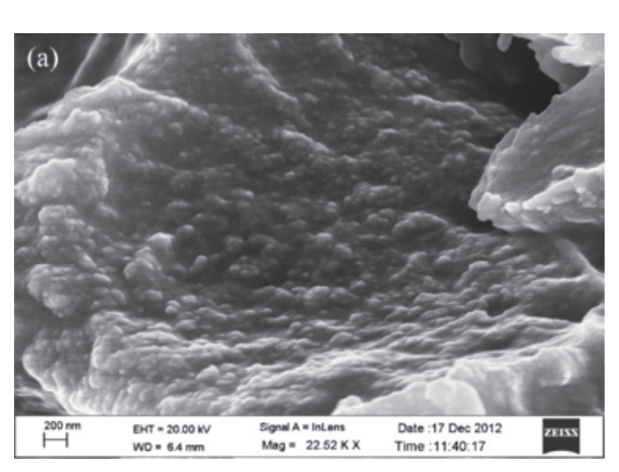

(a)

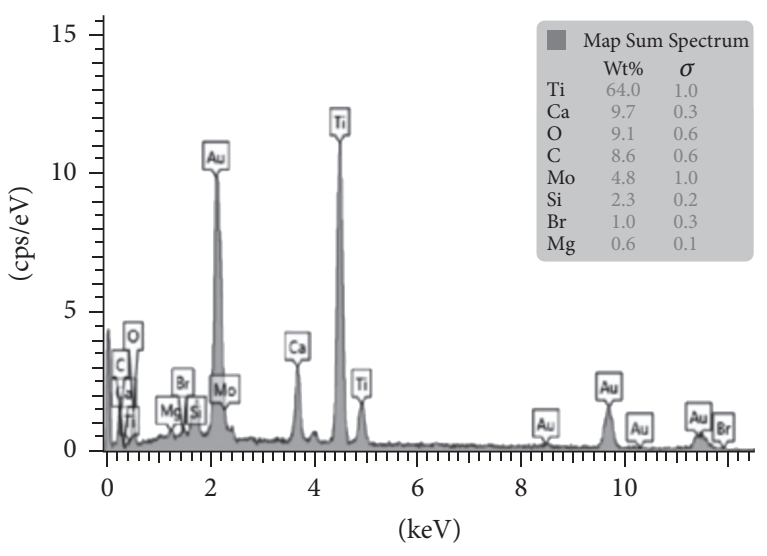

(b)

FIgure 3: (a) SEM analysis (b) EDS measurement after injection of 0.01\% NPs at entrance [57]. @ American Chemical Society. Reproduced by the permission of the publisher.

In summary, an optimal concentration of NPs should be determined to have a maximum recovery. Higher concentrations of NPs have no significant effect on the recovery factor that can increase the cost.

5.2. Ionic Contents. The ionic contents in a reservoir vary depending upon the nature of reservoir and formation. In addition, seawater is usually used as a major component of flooding liquid. Therefore, the impact of salinity on oil recovery is usually determined for all types of chemical EOR core flooding experiments. Hendraningrat and Torsæter evaluated the effects of water salinity and ionic composition on oil recovery using $\mathrm{SiO}_{2}$ based nanofluids [63]. They observed that the oil recovery did not change upon the injection of nanofluids having low salinity $(30,000 \mathrm{ppm})$. The oil recovery increased when the water salinity increased from 30,000 ppm to 100,000 ppm.

Maghzi et al. [43] evaluated the effect of $\mathrm{SiO}_{2} \mathrm{NPs}$ on oil recovery in the presence of salts by conducting a number of polymer flooding tests. They conducted flooding experiments in the presence and absence of $\mathrm{SiO}_{2}$ NPs in polyacrylamide (PAM) solutions with different salinities. The result of their study showed that oil recovery decreased with the increase in salt concentration during the PAM flooding without NPs, whereas in the case of PAM flooding in the presence of NPs, the decreasing rate of oil recovery reduced.

In general, flooding using NPs is sensitive to water salinity and increasing water salinity contributes to a much higher incremental oil recovery $[63,65,93,94]$. However, salinity higher than the critical values can destabilize the dispersion of NPs.

5.3. Type of NPs. Type of NPs influences oil recovery factor and selection of appropriate NPs for typical reservoir conditions is of utmost importance. Bayat et al. studied the displacement effects of three metal oxides $\mathrm{NPs}\left(\mathrm{Al}_{2} \mathrm{O}_{3}, \mathrm{TiO}_{2}\right.$, and $\mathrm{SiO}_{2}$ ) on the quantity and quality of the produced oil from an intermediate limestone sample at different temperatures [41]. 


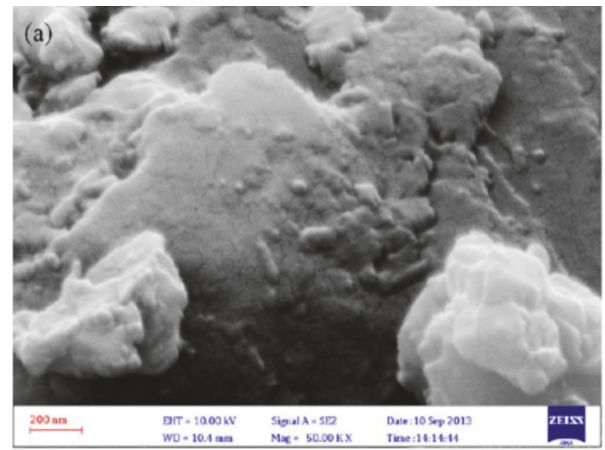

(a)

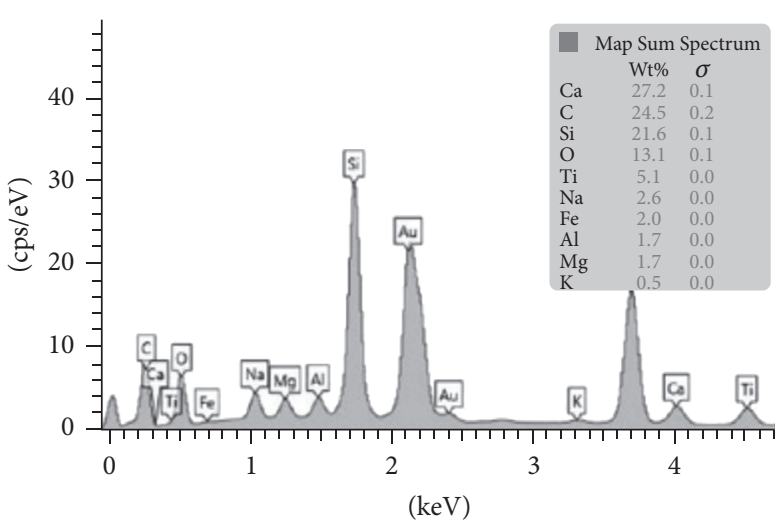

(b)

FIGURE 4: (a) SEM analysis; (b) EDS measurement after injection of $0.01 \%$ NPs at exit [57]. @ American Chemical Society. Reproduced by the permission of the publisher.

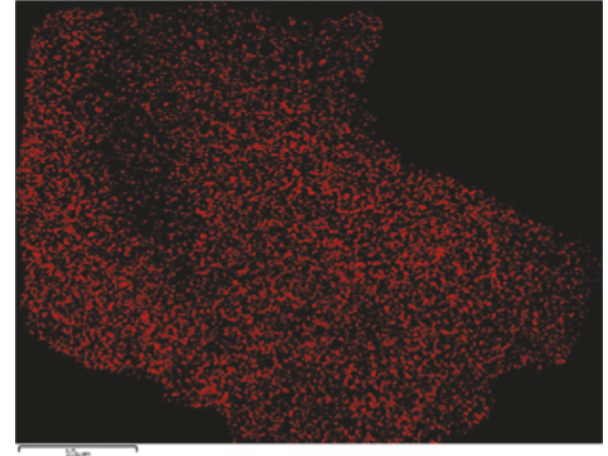

FIgURE 5: EDS map of $\mathrm{Ti}$ using $0.01 \% \mathrm{TiO}_{2}$ injection [57]. (C)American Chemical Society. Reproduced by the permission of the publisher.

The displacement test results showed that the use of brine $(\mathrm{NaCl} 0.3 \mathrm{wt} \%)$ for water flooding resulted in an average of $47.3 \%$ oil recovery at $26^{\circ} \mathrm{C}$. At the same injection conditions $\mathrm{Al}_{2} \mathrm{O}_{3}, \mathrm{TiO}_{2}$, and $\mathrm{SiO}_{2}$ increased the oil recovery to $52.6 \%$, $50.9 \%$, and $48.7 \%$, respectively. The oil recovery at ambient temperature $\left(26^{\circ} \mathrm{C}\right)$ using $\mathrm{Al}_{2} \mathrm{O}_{3}$ nanofluid was 1.5 and 2.25 times greater than that of $\mathrm{TiO}_{2}$ and $\mathrm{SiO}_{2}$, respectively. The highest oil recovery exhibited by the $\mathrm{Al}_{2} \mathrm{O}_{3}$ nanofluid was attributed to its ability to lower the capillary force of oil during the displacement test on the recovery of heavy crude oil. Alomair et al. studied the effect of four nanoparticles $\left(\mathrm{Al}_{2} \mathrm{O}_{3}, \mathrm{TiO}_{2}, \mathrm{SiO}_{2}\right.$, and $\left.\mathrm{NiO}\right)$ on the recovery of heavy oil sandstones. Many flooding experiments were done using the four different nanoparticles at different concentrations. Flooding experiments by $\mathrm{SiO}_{2}$ and flooding experiments by $\mathrm{Al}_{2} \mathrm{O}_{3}$ showed higher recovery when compared to the base recovery, water injection. $\mathrm{SiO}_{2}$ increased the recovery by $0.958 \%$, while $\mathrm{Al}_{2} \mathrm{O}_{3}$ increased the recovery by $4.895 \%$. Since both $\mathrm{SiO}_{2}$ and $\mathrm{Al}_{2} \mathrm{O}_{3}$ showed the highest oil recovery, they decided to mix both nanoparticles and do a flooding experiment where they noted a tremendous oil recovery that is higher than the water injection recovery by $23.724 \%$ [95]. Kazemzadeh and his colleagues investigated the effects of $\mathrm{SiO}_{2}, \mathrm{NiO}$, and $\mathrm{Fe}_{3} \mathrm{O}_{4}$ NPs on the recovery of heavy oil [62]. A glass micromodel was utilized in core flooding setup to simulate oil production in the presence of NPs. It was reported that the flooding based on $\mathrm{SiO}_{2}, \mathrm{NiO}$, and $\mathrm{Fe}_{3} \mathrm{O}_{4}$ improved the oil recovery by $22.6 \%, 14.6 \%$, and $8.1 \%$, respectively, when water injection was set as the reference point. The greater oil recovery displayed by $\mathrm{SiO}_{2}$ was probably due to its effectiveness to reduce interfacial tension and wettability alteration in porous media.

Nazari et al. conducted a preliminary wettability study for eight different NPs and investigated the performance of selected NPs $\left(\mathrm{CaCO}_{3}\right.$ and $\left.\mathrm{SiO}_{2}\right)$ for EOR processes. Oil recovery increased by $8-9 \%$ when NFs were injected. Besides, the spontaneous imbibition results confirmed the active role of $\mathrm{CaCO}_{3}$ and $\mathrm{SiO}_{2}$ NPs. Oil recovery was reported to have increased by factors of 4 and 6 when $\mathrm{CaCO}_{3}$ and $\mathrm{SiO}_{2} \mathrm{NPs}$ were present in the base-fluid, respectively [61]. Roustaei and coworkers tested the performance of modified $\mathrm{SiO}_{2}$ NPs in enhancing oil recovery from two different Iranian light and intermediate oil reservoirs [52]. According to their findings, the total oil recovery increased after the application of modified $\mathrm{SiO}_{2}$ NPs in two core samples saturated with light and intermediate oils. The water flooding recovery of the first plug, which was saturated by light oil, was 54\% and that of the second plug saturated by intermediate oil was $41 \%$. They, however, reported that the oil recovery was increased by $25 \%$ and $14 \%$, respectively, in the first and second core samples. The authors stated that a comparison between the recovery results revealed that NF could produce a significant amount of oil after primary and secondary recovery processes. Further, the capability of NF in enhancing oil recovery was reported to have depended on the oil type and varies from different oil reservoirs. Roustaei and Bagherzadeh [51] reported another similar study which investigated the potentials of $\mathrm{SiO}_{2}$ NFs for EOR applications. 


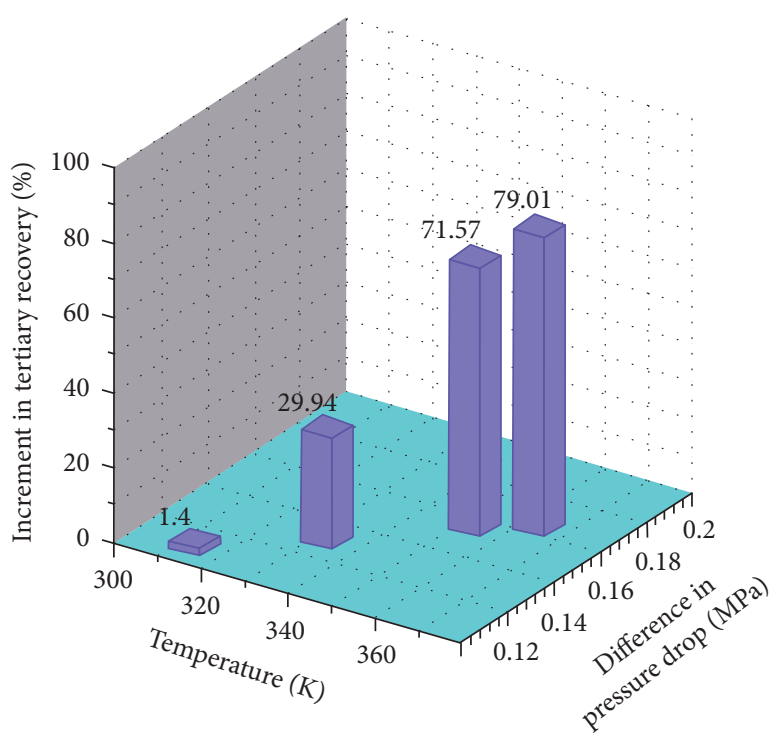

(a)

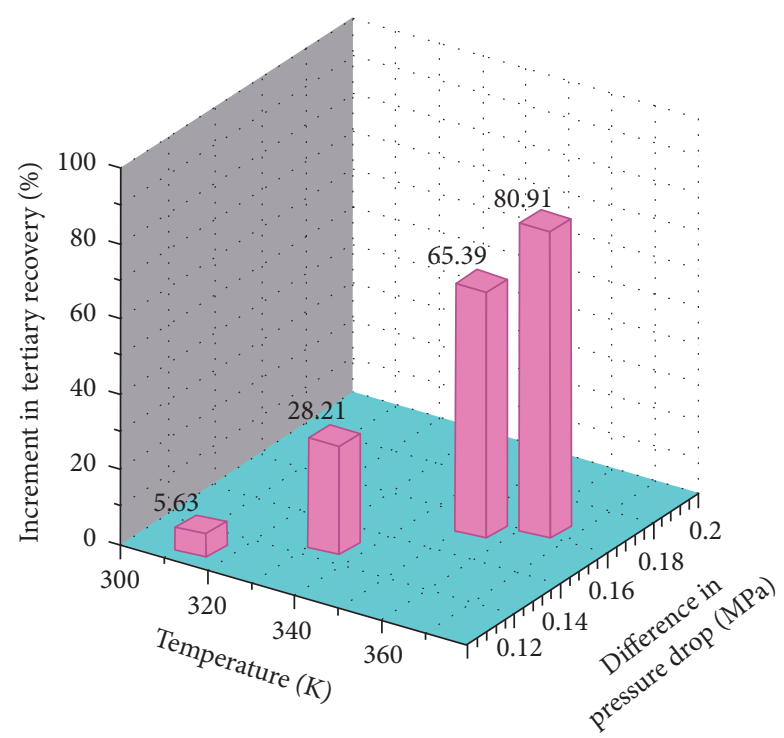

(b)

FIgURE 6: Effect of temperature and $\Delta P$ on recovery: (a) $\mathrm{SiO}_{2}$ emulsion versus $\mathrm{SP}$ system; (b) clay emulsion versus SP system [48]. (CElsevier. Reproduced by permission of the publisher.

In summary performance of different types of nanoparticles depends on the reservoir conditions and nature as well.

5.4. Surfactant-NPs Combined Flooding. The effect of NPs on surfactant efficiency has been investigated in different scenarios. Suleimanov et al. studied the effects of an aqueous solution of anionic surface-active agents with the addition of light nonferrous NPs [96]. Water-free oil recovery of 51\% and $35 \%$ and finite oil recovery of $17 \%$ and $12 \%$ were obtained by employing NFs as a displacement agent in water-surfactant solution. However, in heterogeneous pore medium, waterfree oil recovery was $66 \%$ compared with water and finite oil recovery was $22 \%$ and $17 \%$ according to water and surfactant solution. They concluded that the production rate of oil displaced by NF increased by almost 1.5 -fold in comparison with the aqueous solution of anionic surface-acting agent and 4.7-fold in comparison with water.

Sun et al. studied the stability and displacement behavior of $\mathrm{SiO}_{2}$ NPs with sodium dodecyl sulfate (SDS) using micromodel flooding setup [3]. Flooding results showed that $\mathrm{SiO}_{2} / \mathrm{SDS}$ foam flooding displaced more oil than water flooding or SDS foam flooding. The high recovery was attributed to the improved foam stability and viscoelasticity caused by attached particles. Sandpack flooding tests indicate that $\mathrm{SiO}_{2} / \mathrm{SDS}$ foam has good properties for oil displacement in both homogeneous and heterogeneous formation. The increase in differential pressure and profile control effect exhibited a favorable correspondence with the increase in $\mathrm{SiO}_{2}$ concentration, which led to a higher oil recovery.

Zargartalebi et al. explored the capability of hydrophilic and slightly hydrophobic $\mathrm{SiO}_{2}$ NPs to improve the surfactant performance [54]. Their flooding experiments revealed that NPs could efficiently enhance surfactant flooding with greater additional oil recovery because of the inclusion of NPs into surfactant solutions.

In a study conducted by Sharma and coworkers [48], Pickering emulsion stabilized by $\mathrm{SiO}_{2} \mathrm{NPs}(1 \mathrm{wt} \%)$ and clay (1 wt\%) with surfactant-polymer were evaluated and compared with SP flooding. They conducted several core flood experiments at subsurface equivalent confining pressure of 13.6 MPa and temperature ranging from $313 \mathrm{~K}$ to $363 \mathrm{~K}$ in Berea sandstone cores. In order to understand the correlation between the pressure drop and oil recovery for the two flooding systems examined, they plotted the increment oil recovery as a function of the difference in pressure drop at each temperature condition of the two flood systems (i.e., the SP and Pickering emulsion, as demonstrated in Figure 6). Results showed that the larger difference in pressure drop between these two flood systems occurred at a higher temperature. In addition, with an increase in temperatures, the difference in pressure drop of both flood systems resulted in the improvement of oil recovery from $1.4 \%$ to $79.01 \%$ and $5.63 \%$ to $80.91 \%$ for $\mathrm{SiO}_{2}$ (Figure 6(a)) and clay stabilized emulsions (Figure 6(b)), respectively.

In the work of Pei et al. [44], the effects of $\mathrm{SiO}_{2}$ NPs on the surfactant-stabilized emulsion were studied for enhanced heavy oil recovery. They used the core flooding and microscopic visualization tests to investigate the displacement mechanisms by $\mathrm{SiO}_{2}$ NPs surfactant-stabilized emulsion. They conducted a series of flooding tests in cores with absolute permeability varied from $100 \mathrm{mD}$ to $1100 \mathrm{mD}$. In all the cases that were tested in their study, $0.5 \mathrm{PV}$ emulsion slug was injected after the initial water flooding while $0.1 \mathrm{wt} \%$ of pure cationic surfactant hexadecyltrimethylammonium bromide was employed for surfactant-stabilized emulsion flooding and $0.1 \mathrm{wt} \%$ pure cationic surfactant 


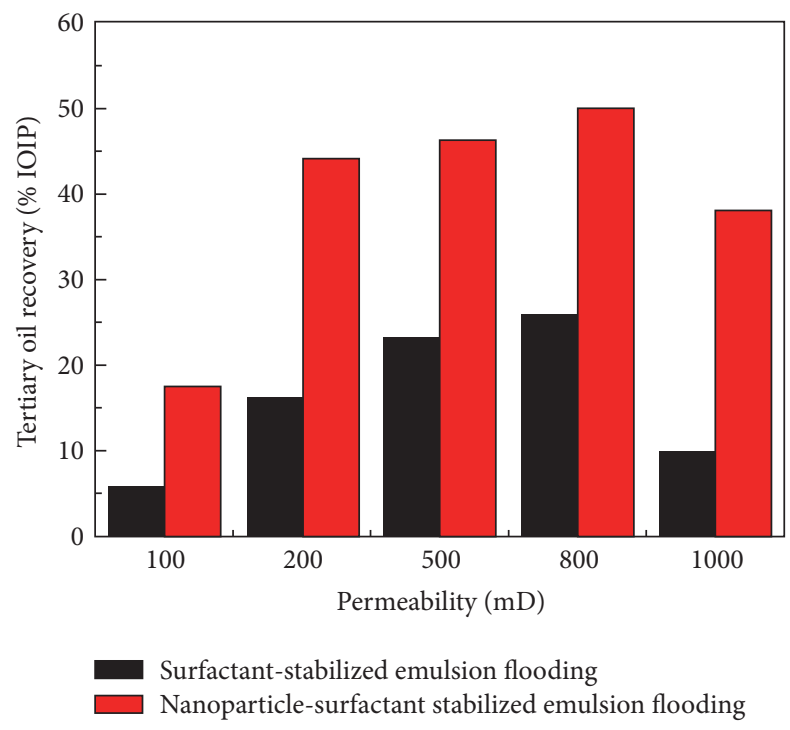

Figure 7: Oil recovery using different types of emulsions [44]. (C) Elsevier. Reproduced by the permission of the publisher.

hexadecyltrimethylammonium bromide mixed with $0.4 \mathrm{wt} \%$ $\mathrm{SiO}_{2}$ was used for nanoparticle-surfactant-stabilized emulsion flooding. Figure 7 shows the tertiary oil recovery of the core flooding tests plotted as a function of permeability. Their study revealed that the emulsion stabilized by NPs and surfactant had a better displacement performance than the emulsion stabilized by surfactant alone for all the permeability ranges examined.

In summary, the observations from the core flooding results revealed that the quantities, as well as the concentrations and the types of NPs, played a significant role in improving oil recovery. The addition of salts has enormous influence on the performance of NPs during the core flooding experiments and this to a large extent affects the amount of oil that can be recovered. Likewise, the interaction and transport mechanism of NPs within reservoir rocks are also contributing factors that will affect additional oil recovery. Though a significant number of core flooding experiments were reported in the literature describing different aspects of NPs injection, there is a lack of understanding how oil recovery is affected using NPs at different conditions. For example, literature is not sufficient to explain how recovery is affected by changing the flow rate of NFs, changing pore pressure, and changing injection sequence of NFs. On the other hand, these parameters are well investigated and understood for the surfactant, polymer, and combined surfactant-polymer flooding.

\section{Stability}

It is very important when choosing a chemical for enhanced oil recovery to study its performance under reservoir conditions, where temperature and salinity are normally very high. Mcelfresh and his group studied the stability of three types of nanoparticles in both sandstones and carbonates in harsh environments, that is, at high temperature and high salinity. They studied soft particle microemulsion with basic $\mathrm{SiO}_{2}$ nanoparticles, surfactant package with colloidal $\mathrm{SiO}_{2}$ nanoparticles, and surfactant package with surface modified $\mathrm{SiO}_{2}$ nanoparticles. Both imbibition tests and core flooding experiments were done to investigate the performance of the three nanoparticles. It was found that the basic $\mathrm{SiO}_{2}$ nanoparticles failed to stabilize in the harsh environment due to their exposed surface charge. Surfactant package with colloidal $\mathrm{SiO}_{2}$ nanoparticles was found to be stable by changing the fluid acidity; however, it was not able to withstand the extremes of salinity and temperature. The third nanoparticles, surfactant package with surface modified $\mathrm{SiO}_{2}$ nanoparticles, was the best in terms of stability at the harsh environment and it was used in flooding experiments where it showed good oil recovery results [97].

\section{Field Applications, Challenges, and Perspectives}

For successful implementation of NPs in the field, a complete understanding of field conditions and process variables is necessary. The difference between the field and laboratory conditions must be assessed that can be helpful in scale-up of laboratory experiments. Applications of nanoparticles in EOR did not get much attention in the past due to inadequate understanding of mechanism, high chemical costs, and low crude oil prices. In last few years, the number of publications on NPs application in EOR has been increased extensively. These publications are mainly based on screening and evaluation of different NPs using wettability, IFT, and rheological measurements. In addition, a number of experiments were performed to determine the oil recovery using different reservoir rocks including carbonates and sandstones. However, no field trial of EOR using NPs is reported in the open literature. Considering the rise in a number of publications and good results obtained from laboratory experiments, NPs are potentially future candidates in EOR along with surfactants and polymers.

Although good results have been obtained in the laboratory using NPs, a number of challenges exist that should be addressed to implement NPs in oil fields. Current laboratory experiments show that, in low-temperature and low-low salinity conditions, NPs dispersions are stable for a significant time. However, the stability of the NPs at harsh reservoir conditions is one of the major challenges in the implementation of NPs in EOR. Various approaches were adopted to stabilize nanoparticles dispersion but failed to address high temperature and high salinity conditions. Based on some experimental data obtained in our laboratory, NPs dispersed in water-soluble polymers such as polyacrylamide are stable for a significant time. Polymer-NPs combined flooding can address the issue of NPs dispersion stability. Another possible solution to achieve stability is polymer coatings that can potentially improve the stability and surface properties of NPs for EOR. Most of the investigated NPs are tailored which are comparatively expensive. The cost-effective NPs having good EOR properties are one of the main challenges in field implementation. The future challenge is to develop 
cheap techniques for large-scale production of NPs for field applications where the cost is the most important factor. In addition, some of the NPs are toxic for humans. Mechanism of NPs adsorption on different rocks at different conditions remains poorly understood. Literature is unable to explain how adsorption will have an effect by changing rock type, temperature, and salinity. Finally, scale-up of NPs laboratory experiments to real field application is a challenge itself.

Addressing these challenges can eventually lead to the development of cost-effective NPs formulation with lower adsorption and less aggregation with many desirable properties such as lower IFT and enhanced viscosity.

\section{Concluding Remarks}

Different types of nanoparticles used in chemical EOR are reviewed. The impact of nanoparticles on rheology, interfacial tension, wettability alteration, and oil recovery is discussed. Recent laboratory results have shown that nanoparticles can be used to increase the recovery from the oil reservoir. Use of nanoparticles in displacement fluids can lower the interfacial tension, improve the rheological properties, and alter the wettability of the rock to a more water-water state. Nanoparticles can also lower the adsorption of surfactant on reservoir rock as well. Stability of nanoparticles dispersion is one of the main challenges that need to be addressed. In addition, the cost of nanoparticles is another important issue in practical applications. $\mathrm{SiO}_{2}$ nanoparticles are the most investigated nanoparticles for EOR applications. The future research in this field will focus on investigating the cheap nanoparticles such as nanoclays. Despite the fact that the number of publications on the evaluation of nanoparticles in enhanced oil recovery has increased, no field trial is reported to date.

\section{Nomenclature}

$\begin{array}{ll}\text { A: } & \text { Ambient temperature } \\ \text { CMC: } & \text { Critical micelle concentration } \\ \text { EDS: } & \text { Energy dispersive spectrometry } \\ \text { EOR: } & \text { Enhanced oil recovery } \\ G^{\prime}: & \text { Storage modulus } \\ G^{\prime \prime}: & \text { Viscous modulus } \\ \text { HPHT: } & \text { High pressure high temperature } \\ \text { IFT: } & \text { Interfacial tension } \\ k_{\mathrm{o}}: & \text { Permeability (oil) } \\ k_{\mathrm{w}}: & \text { Permeability (water) } \\ \text { MWCNT: } & \text { Multiwalled carbon nanotubes } \\ N_{\mathrm{ca}}: & \text { Capillary number } \\ \text { NFs: } & \text { Nanofluids } \\ \text { NPs: } & \text { Nanoparticles } \\ \text { PAM: } & \text { Polyacrylamide } \\ \text { PV: } & \text { Pore volume } \\ \text { PVA: } & \text { Polyvinyl alcohol } \\ \text { SDS: } & \text { Sodium dodecyl sulfate } \\ \text { SEM: } & \text { Scanning electron microscope } \\ \text { SP: } & \text { Surfactant-polymer } \\ \mu: & \text { Dynamic viscosity } \\ \mu_{\mathrm{o}}: & \text { Viscosity (oil) }\end{array}$

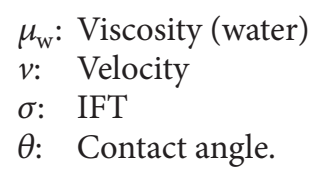

\section{Conflicts of Interest}

The authors declare that they have no conflicts of interest.

\section{Acknowledgments}

The authors would like to thank Center for Integrative Petroleum Research for providing financial resources for this research.

\section{References}

[1] H. Shamsijazeyi, C. A. Miller, M. S. Wong, J. M. Tour, and R. Verduzco, "Polymer-coated nanoparticles for enhanced oil recovery," Journal of Applied Polymer Science, vol. 131, no. 15, Article ID 40576, 2014.

[2] E. Joonaki and S. Ghanaatian, "The application of nanofluids for enhanced oil recovery: Effects on interfacial tension and coreflooding process," Petroleum Science and Technology, vol. 32, no. 21, pp. 2599-2607, 2014.

[3] Q. Sun, Z. Li, S. Li, L. Jiang, J. Wang, and P. Wang, "Utilization of surfactant-stabilized foam for enhanced oil recovery by adding nanoparticles," Energy and Fuels, vol. 28, no. 4, pp. 2384-2394, 2014.

[4] M. S. Kamal, A. S. Sultan, and I. A. Hussein, "Screening of amphoteric and anionic surfactants for cEOR applications using a novel approach," Colloids and Surfaces A: Physicochemical and Engineering Aspects, vol. 476, pp. 17-23, 2015.

[5] M. S. Kamal, A. S. Sultan, U. A. Al-Mubaiyedh, and I. A. Hussein, "Review on polymer flooding: Rheology, adsorption, stability, and field applications of various polymer systems," Polymer Reviews, vol. 55, no. 3, pp. 491-530, 2015.

[6] H. Gong, Y. Li, M. Dong, S. Ma, and W. Liu, "Effect of wettability alteration on enhanced heavy oil recovery by alkaline flooding," Colloids and Surfaces A: Physicochemical and Engineering Aspects, vol. 488, pp. 28-35, 2016.

[7] M. Bayat, M. Lashkarbolooki, A. Z. Hezave, and S. Ayatollahi, "Investigation of gas injection flooding performance as enhanced oil recovery method," Journal of Natural Gas Science and Engineering, vol. 29, pp. 37-45, 2016.

[8] T. Lu, Z. Li, S. Li, P. Wang, Z. Wang, and S. Liu, "Enhanced heavy oil recovery after solution gas drive by water flooding," Journal of Petroleum Science and Engineering, vol. 137, pp. 113-124, 2016.

[9] P. J. Liyanage, J. Lu, G. W. P. Arachchilage, U. P. Weerasooriya, and G. A. Pope, "A novel class of large-hydrophobe tristyrylphenol (TSP) alkoxy sulfate surfactants for chemical enhanced oil recovery," Journal of Petroleum Science and Engineering, vol. 128, pp. 73-85, 2015.

[10] A. Goudarzi, M. Delshad, K. K. Mohanty, and K. Sepehrnoori, "Surfactant oil recovery in fractured carbonates: experiments and modeling of different matrix dimensions," Journal of Petroleum Science and Engineering, vol. 125, pp. 136-145, 2015.

[11] C. Wang, X. Li, P. Li, and Y. Niu, "Interactions between fluorinated cationic guar gum and surfactants in the dilute and semi-dilute solutions," Carbohydrate Polymers, vol. 99, pp. 638645, 2014. 
[12] A. A. Olajire, "Review of ASP EOR (alkaline surfactant polymer enhanced oil recovery) technology in the petroleum industry: prospects and challenges," Energy, vol. 77, pp. 963-982, 2014.

[13] A. Kamari, F. Gharagheizi, A. Shokrollahi, M. Arabloo, and A. H. Mohammadi, "Integrating a robust model for predicting surfactant-polymer flooding performance," Journal of Petroleum Science and Engineering, vol. 137, pp. 87-96, 2016.

[14] P. Bikkina, J. Wan, Y. Kim, T. J. Kneafsey, and T. K. Tokunaga, "Influence of wettability and permeability heterogeneity on miscible $\mathrm{CO}_{2}$ flooding efficiency," Fuel, vol. 166, pp. 219-226, 2015.

[15] M. A. Ahmadi and S. R. Shadizadeh, "Implementation of a highperformance surfactant for enhanced oil recovery from carbonate reservoirs," Journal of Petroleum Science and Engineering, vol. 110, pp. 66-73, 2013.

[16] M. A. Ahmadi and S. R. Shadizadeh, "Experimental investigation of adsorption of a new nonionic surfactant on carbonate minerals," Fuel, vol. 104, pp. 462-467, 2013.

[17] M. A. Ahmadi, S. Zendehboudi, A. Shafiei, and L. James, "Nonionic surfactant for enhanced oil recovery from carbonates: Adsorption kinetics and equilibrium," Industrial and Engineering Chemistry Research, vol. 51, no. 29, pp. 9894-9905, 2012.

[18] S. Zendehboudi, M. A. Ahmadi, A. R. Rajabzadeh, N. Mahinpey, and I. Chatzis, "Experimental study on adsorption of a new surfactant onto carbonate reservoir samples-application to EOR," Canadian Journal of Chemical Engineering, vol. 91, no. 8, pp. 1439-1449, 2013.

[19] M. S. Kamal, A. S. Sultan, U. A. Al-Mubaiyedh, I. A. Hussein, and Y. Feng, "Rheological Properties of Thermoviscosifying Polymers in High-temperature and High-salinity Environments," Canadian Journal of Chemical Engineering, vol. 93, no. 7, pp. 1194-1200, 2015.

[20] M. S. Kamal, A. S. Sultan, U. A. Al-Mubaiyedh, I. A. Hussien, and M. Pabon, "Evaluation of rheological and thermal properties of a new fluorocarbon surfactant-polymer system for EOR applications in high-temperature and high-salinity oil reservoirs," Journal of Surfactants and Detergents, vol. 17, no. 5, pp. 985-993, 2014.

[21] Y. Wang, Y. Feng, B. Wang, and Z. Lu, "A novel thermoviscosifying water-soluble polymer: Synthesis and aqueous solution properties," Journal of Applied Polymer Science, vol. 116, no. 6, pp. 3516-3524, 2010.

[22] I. Silva, M. de Melo, J. Luvizotto, and E. Lucas, "Polymer Flooding: A Sustainable Enhanced Oil Recovery in the Current Scenario," in Proceedings of the Latin American \& Caribbean Petroleum Engineering Conference, Buenos Aires, Argentina, April 2007.

[23] M. de Melo and E. Lucas, "Characterization and selection of polymers for future research on enhanced oil recovery," Chemistry Chemical Technology, vol. 2, pp. 295-303, 2008.

[24] M. D. Melo and E. Lucas, "Characterization and selection of polymers for future," Chemistry Chemical Technology, vol. 2, no. 4, pp. 295-303, 2008.

[25] Y. Wu, P. J. Shuler, M. Blanco, Y. Tang, and W. A. Goddard III, "An experimental study of wetting behavior and surfactant EOR in carbonates with model compounds," SPE Journal, vol. 13, no. 1, pp. 26-34, 2008.

[26] A. R. Sagi, M. Puerto, Y. Bian et al., "Laboratory studies for surfactant flood in low-temperature, low-salinity fractured carbonate reservoir," in Proceedings of the International Symposium on Oilfield Chemistry 2013, pp. 230-249, usa, April 2013.
[27] B. Gao and M. M. Sharma, "A new family of anionic surfactants for enhanced-oil-recovery applications," SPE Journal, vol. 18, no. 5, pp. 829-840, 2013.

[28] A. O. Al-Amodi, U. A. Al-Mubaiyedh, A. S. Sultan, M. S. Kamal, and I. A. Hussein, "Novel fluorinated surfactants for enhanced oil recovery in carbonate reservoirs," Canadian Journal of Chemical Engineering, vol. 94, no. 3, pp. 454-460, 2016.

[29] M. S. Kamal, I. A. Hussien, A. S. Sultan, and M. Han, "Rheological study on ATBS-AM copolymer-surfactant system in high-temperature and high-salinity environment," Journal of Chemistry, Article ID 801570, 2013.

[30] X. Su, B. Wang, Z. Lu, L. Wei, and Y. Feng, "A new cationic gemini surfmer: Synthesis and surface activities," Journal of Surfactants and Detergents, vol. 14, no. 1, pp. 73-76, 2011.

[31] F. Shehzad, I. A. Hussein, M. S. Kamal, W. Ahmad, A. S. Sultan, and M. S. Nasser, "Polymeric Surfactants and Emerging Alternatives used in the Demulsification of Produced Water: A Review," Polymer Reviews, pp. 1-39, 2017.

[32] M. S. Kamal, I. A. Hussein, and A. S. Sultan, "Review on Surfactant Flooding," in Phase Behavior, Retention, IFT and Field Applications, Energy Fuels, Review on Surfactant Flooding, Phase Behavior, 2017.

[33] J. B. Crews and T. Huang, "Performance enhancements of viscoelastic surfactant stimulation fluids with nanoparticles," in Proceedings of the Europec/EAGE Conference and Exhibition, Rome, Italy.

[34] M. Y. Kanj, J. J. Funk, and Z. Al-Yousif, "Nanofluid Coreflood Experiments in the ARAB-D," in Proceedings of the SPE Saudi Arabia Section Technical Symposium, Al-Khobar, Saudi Arabia.

[35] Q. Lan, F. Yang, S. Zhang, S. Liu, J. Xu, and D. Sun, "Synergistic effect of silica nanoparticle and cetyltrimethyl ammonium bromide on the stabilization of $\mathrm{O} / \mathrm{W}$ emulsions," Colloids and Surfaces A: Physicochemical and Engineering Aspects, vol. 302, no. 1-3, pp. 126-135, 2007.

[36] R. Hashemi, N. N. Nassar, and P. P. Almao, "Nanoparticle technology for heavy oil in-situ upgrading and recovery enhancement: opportunities and challenges," Applied Energy, vol. 133, pp. 374-387, 2014.

[37] M. Ershadi, M. Alaei, A. Rashidi, A. Ramazani, and S. Khosravani, "Carbonate and sandstone reservoirs wettability improvement without using surfactants for Chemical Enhanced Oil Recovery (C-EOR)," Fuel, vol. 153, article no. 9007, pp. 408-415, 2015.

[38] S. K. Singh, R. M. Ahmed, and F. Growcock, "Vital role of nanopolymers in drilling and stimulations fluid applications," in Proceedings of the SPE Annual Technical Conference and Exhibition, Florence, Italy.

[39] A. Maghzi, S. Mohammadi, M. H. Ghazanfari, R. Kharrat, and M. Masihi, "Monitoring wettability alteration by silica nanoparticles during water flooding to heavy oils in five-spot systems: A pore-level investigation," Experimental Thermal and Fluid Science, vol. 40, pp. 168-176, 2012.

[40] N. A. Ogolo, O. A. Olafuyi, and M. O. Onyekonwu, "Enhanced oil recovery using nanoparticles," in Proceedings of the SPE Saudi Arabia Section Technical Symposium and Exhibition 2012, pp. 276-284, sau, April 2012.

[41] A. E. Bayat, R. Junin, A. Samsuri, A. Piroozian, and M. Hokmabadi, "Impact of metal oxide nanoparticles on enhanced oil recovery from limestone media at several temperatures," Energy and Fuels, vol. 28, no. 10, pp. 6255-6266, 2014. 
[42] B. Moradi, P. Pourafshary, F. Jalali, M. Mohammadi, and M. A. Emadi, "Experimental study of water-based nanofluid alternating gas injection as a novel enhanced oil-recovery method in oil-wet carbonate reservoirs," Journal of Natural Gas Science and Engineering, vol. 27, pp. 64-73, 2015.

[43] A. Maghzi, R. Kharrat, A. Mohebbi, and M. H. Ghazanfari, “The impact of silica nanoparticles on the performance of polymer solution in presence of salts in polymer flooding for heavy oil recovery," Fuel, vol. 123, pp. 123-132, 2014.

[44] H. Pei, G. Zhang, J. Ge, J. Zhang, and Q. Zhang, "Investigation of synergy between nanoparticle and surfactant in stabilizing oilin-water emulsions for improved heavy oil recovery," Colloids and Surfaces A: Physicochemical and Engineering Aspects, vol. 484, pp. 478-484, 2015.

[45] T. Sharma and J. S. Sangwai, "Effects of electrolytes on the stability and dynamic rheological properties of an oil-in-water pickering emulsion stabilized by a nanoparticle-surfactant-polymer system," Industrial and Engineering Chemistry Research, vol. 54, no. 21, pp. 5842-5852, 2015.

[46] A. Maghzi, A. Mohebbi, R. Kharrat, and M. H. Ghazanfari, "An experimental investigation of silica nanoparticles effect on the rheological behavior of polyacrylamide solution to enhance heavy oil recovery," Petroleum Science and Technology, vol. 31, no. 5, pp. 500-508, 2013.

[47] G. Cheraghian, S. S. Khalili Nezhad, M. Kamari, M. Hemmati, M. Masihi, and S. Bazgir, "Effect of nanoclay on improved rheology properties of polyacrylamide solutions used in enhanced oil recovery," Journal of Petroleum Exploration and Production Technology, vol. 5, no. 2, pp. 189-196, 2015.

[48] T. Sharma, G. S. Kumar, and J. S. Sangwai, "Comparative effectiveness of production performance of Pickering emulsion stabilized by nanoparticle-surfactant-polymerover surfactantpolymer (SP) flooding for enhanced oil recoveryfor Brownfield reservoir," Journal of Petroleum Science and Engineering, vol. 129, pp. 221-232, 2015.

[49] B. Ju, T. Fan, and M. Ma, "Enhanced oil recovery by flooding with hydrophilic nanoparticles," China Particuology, vol. 4, no. 1, pp. 41-46, 2006.

[50] M. O. Onyekonwu and N. A. Ogolo, "Investigating the Use of Nanoparticles in Enhancing Oil Recovery," in Proceedings of the Nigeria Annual International Conference and Exhibition, Tinapa - Calabar, Nigeria.

[51] A. Roustaei and H. Bagherzadeh, "Experimental investigation of $\mathrm{SiO} 2$ nanoparticles on enhanced oil recovery of carbonate reservoirs," Journal of Petroleum Exploration and Production Technology, vol. 5, no. 1, pp. 27-33, 2015.

[52] A. Roustaei, S. Saffarzadeh, and M. Mohammadi, "An evaluation of modified silica nanoparticles' efficiency in enhancing oil recovery of light and intermediate oil reservoirs," Egyptian Journal of Petroleum, vol. 22, no. 3, pp. 427-433, 2013.

[53] S. Mohammadi, A. Maghzi, M. H. Ghazanfari, M. Masihi, and R. Kharrat, "On the effect of silica nanoparticles on wettability alteration during water flooding to heavy oils-A micromodel study," in Proceedings of the 74th European Association of Geoscientists and Engineers Conference and Exhibition 2012 Incorporating SPE EUROPEC 2012: Responsibly Securing Natural Resources, pp. 3943-3947, dnk, June 2012.

[54] M. Zargartalebi, R. Kharrat, and N. Barati, "Enhancement of surfactant flooding performance by the use of silica nanoparticles," Fuel, vol. 143, pp. 21-27, 2015.
[55] H. Ma, M. Luo, and L. L. Dai, "Influences of surfactant and nanoparticle assembly on effective interfacial tensions," Physical Chemistry Chemical Physics, vol. 10, no. 16, pp. 2207-2213, 2008.

[56] P. Esmaeilzadeh, N. Hosseinpour, A. Bahramian, Z. Fakhroueian, and S. Arya, "Effect of $\mathrm{ZrO} 2$ nanoparticles on the interfacial behavior of surfactant solutions at air-water and n-heptane-water interfaces," Fluid Phase Equilibria, vol. 361, pp. 289$295,2014$.

[57] H. Ehtesabi, M. M. Ahadian, V. Taghikhani, and M. H. Ghazanfari, "Enhanced heavy oil recovery in sandstone cores using TiO2 nanofluids," Energy and Fuels, vol. 28, no. 1, pp. 423-430, 2014.

[58] G. Cheraghian, M. Hemmati, M. Masihi, and S. Bazgir, "An experimental investigation of the enhanced oil recovery and improved performance of drilling fluids using titanium dioxide and fumed silica nanoparticles," Journal of Nanostructure in Chemistry, vol. 3, no. 1, p. 78, 2013.

[59] H. A. Son, K. Y. Yoon, G. J. Lee et al., "The potential applications in oil recovery with silica nanoparticle and polyvinyl alcohol stabilized emulsion," Journal of Petroleum Science and Engineering, vol. 126, pp. 152-161, 2015.

[60] H. Son, H. Kim, G. Lee, J. Kim, and W. Sung, "Enhanced oil recovery using nanoparticle-stabilized oil/water emulsions," Korean Journal of Chemical Engineering, vol. 31, no. 2, pp. 338342, 2014.

[61] M. R. Nazari, A. Bahramian, Z. Fakhroueian, A. Karimi, and S. Arya, "Comparative study of using nanoparticles for enhanced oil recovery: wettability alteration of carbonate rocks," Energy and Fuels, vol. 29, no. 4, pp. 2111-2119, 2015.

[62] Y. Kazemzadeh, S. E. Eshraghi, K. Kazemi, S. Sourani, M. Mehrabi, and Y. Ahmadi, "Behavior of asphaltene adsorption onto the metal oxide nanoparticle surface and its effect on heavy oil recovery," Industrial and Engineering Chemistry Research, vol. 54, no. 1, pp. 233-239, 2015.

[63] L. Hendraningrat and O. Torsæter, "A study of water chemistry extends the benefits of using silica-based nanoparticles on enhanced oil recovery," Applied Nanoscience, vol. 6, no. 1, pp. 8395, 2016.

[64] G. Cheraghian and L. Hendraningrat, "A review on applications of nanotechnology in the enhanced oil recovery part B: effects of nanoparticles on flooding," International Nano Letters, vol. 6, no. 1, pp. 1-10, 2016.

[65] L. Hendraningrat and O. Torsæter, "Effects of the initial rock wettability on silica-based nanofluid-enhanced oil recovery processes at reservoir temperatures," Energy and Fuels, vol. 28, no. 10, pp. 6228-6241, 2014.

[66] M. Mohajeri, M. Hemmati, and A. S. Shekarabi, "An experimental study on using a nanosurfactant in an EOR process of heavy oil in a fractured micromodel," Journal of Petroleum Science and Engineering, vol. 126, pp. 162-173, 2015.

[67] S. C. Ayirala and D. N. Rao, "Multiphase flow and wettability effects of surfactants in porous media," Colloids and Surfaces A: Physicochemical and Engineering Aspects, vol. 241, no. 1-3, pp. 313-322, 2004.

[68] G. Zhang, J. Yu, C. Du, and R. Lee, "Formulation of surfactants for very low/high salinity surfactant flooding without alkali," in Proceedings of the International Symposium on Oilfield Chemistry 2015, pp. 399-414, usa, April 2015.

[69] P. Chen and K. K. Mohanty, "Surfactant-enhanced oil recovery from fractured oil-wet carbonates: effects of low ift and wettability alteration," in Proceedings of the SPE International Symposium on Oilfield Chemistry, The Woodlands, Texas, USA. 
[70] X. Wu, M. Han, B. H. Zahrani, and L. Guo, "Effect of surfactantpolymer interaction on the interfacial properties for chemical EOR," in Proceedings of the in SPE Middle East Oil Gas Show and Conference Society of Petroleum Engineers, 2015.

[71] R. Cao, H. Yang, W. Sun, and Y. Zee Ma, "A new laboratory study on alternate injection of high strength foam and ultralow interfacial tension foam to enhance oil recovery," Journal of Petroleum Science and Engineering, vol. 125, pp. 75-89, 2015.

[72] F.-Q. Yuan, Y.-Q. Cheng, H.-Y. Wang et al., "Effect of organic alkali on interfacial tensions of surfactant solutions against crude oils," Colloids and Surfaces A: Physicochemical and Engineering Aspects, vol. 470, pp. 171-178, 2015.

[73] M. A. Ahmadi, M. Galedarzadeh, and S. R. Shadizadeh, "Wettability alteration in carbonate rocks by implementing new derived natural surfactant: enhanced oil recovery applications," Transport in Porous Media, vol. 106, no. 3, pp. 645-667, 2015.

[74] M. S. Kamal, "A review of gemini surfactants: potential application in enhanced oil recovery," Journal of Surfactants and Detergents, vol. 19, no. 2, pp. 223-236, 2016.

[75] J. H. Clint, E. L. Neustadter, and P. A. Wheeler, "Interaction of enhanced oil recovery surfactants with model crude oil surfactants," Colloids and Surfaces, vol. 11, no. 1-2, pp. 129-136, 1984.

[76] J. Menezes, J. Yan, and M. Sharma, "The mechanism of wettability alteration due to surfactants in oil-based muds," in Proceedings of the SPE International Symposium on Oilfield Chemistry, Houston, Texas.

[77] B. Song, X. Hu, X. Shui, Z. Cui, and Z. Wang, "A new type of renewable surfactants for enhanced oil recovery: dialkylpolyoxyethylene ether methyl carboxyl betaines," Colloids and Surfaces A: Physicochemical and Engineering Aspects, vol. 489, pp. 433-440, 2016.

[78] S. M. Shakil Hussain, M. A. Animashaun, M. S. Kamal, N. Ullah, I. A. Hussein, and A. S. Sultan, "Synthesis, characterization and surface properties of amidosulfobetaine surfactants bearing odd-number hydrophobic tail," Journal of Surfactants and Detergents, vol. 19, no. 2, pp. 413-420, 2016.

[79] M. A. Ahmadi, Y. Arabsahebi, S. R. Shadizadeh, and S. Shokrollahzadeh Behbahani, "Preliminary evaluation of mulberry leafderived surfactant on interfacial tension in an oil-aqueous system: EOR application," Fuel, vol. 117, pp. 749-755, 2014.

[80] M. A. Ahmadi and S. Shadizadeh, "Experimental and theoretical study of a new plant derived surfactant adsorption on quartz surface: kinetic and isotherm methods," Journal of Dispersion Science and Technology, vol. 36, no. 3, pp. 441-452, 2015.

[81] M. A. Ahmadi and S. R. Shadizadeh, "Adsorption of novel nonionic surfactant and particles mixture in carbonates: Enhanced oil recovery implication," Energy and Fuels, vol. 26, no. 8, pp. 4655-4663, 2012.

[82] M. A. Ahmadi and S. R. Shadizadeh, "Induced effect of adding nano silica on adsorption of a natural surfactant onto sandstone rock: experimental and theoretical study," Journal of Petroleum Science and Engineering, vol. 112, pp. 239-247, 2013.

[83] M. Zargartalebi, N. Barati, and R. Kharrat, "Influences of hydrophilic and hydrophobic silica nanoparticles on anionic surfactant properties: interfacial and adsorption behaviors," Journal of Petroleum Science and Engineering, vol. 119, pp. 3643, 2014.

[84] Y. Wang, H. Xu, W. Yu, B. Bai, X. Song, and J. Zhang, "Surfactant induced reservoir wettability alteration: Recent theoretical and experimental advances in enhanced oil recovery," Petroleum Science, vol. 8, no. 4, pp. 463-476, 2011.
[85] E. C. Donaldson, R. D. Thomas, and P. B. Lorenz, "Wettability determination and its effect on recovery efficiency," Society of Petroleum Engineers Journal, vol. 9, no. 01, pp. 13-20, 2013.

[86] M. Mohammed and T. Babadagli, "Wettability alteration: A comprehensive review of materials/methods and testing the selected ones on heavy-oil containing oil-wet systems," Advances in Colloid and Interface Science, vol. 220, pp. 54-77, 2015.

[87] B.-F. Hou, Y.-F. Wang, and Y. Huang, "Mechanistic study of wettability alteration of oil-wet sandstone surface using different surfactants," Applied Surface Science, vol. 330, pp. 56-64, 2015.

[88] Y. Wang, X.-Y. Zheng, X.-G. Li, Q.-Z. Jiang, and Y.-Q. Wu, "Effects of ethylene-bis (alkyl benzene sulfonate) Gemini surfactant on wettability of solid surfaces," Oilfield Chemistry, vol. 3, p. 21, 2009.

[89] R. Zhang, N. Qin, L. Peng, K. Tang, and Z. Ye, "Wettability alteration by trimeric cationic surfactant at water-wet/oil-wet mica mineral surfaces," Applied Surface Science, vol. 258, no. 20, pp. 7943-7949, 2012.

[90] M. Delshad, N. F. Najafabadi, G. A. Anderson, G. A. Pope, and K. Sepehrnoori, "Modeling wettability alteration by surfactants in naturally fractured reservoirs," SPE Reservoir Evaluation and Engineering, vol. 12, no. 3, pp. 361-370, 2009.

[91] M. Salehi, S. J. Johnson, and J.-T. Liang, "Mechanistic study of wettability alteration using surfactants with applications in naturally fractured reservoirs," Langmuir, vol. 24, no. 24, pp. 14099-14107, 2008.

[92] G. R. Gaafar, R. D. Tewari, and Z. Md Zain, "Overview of advancement in core analysis and its importance in reservoir characterisation for maximising recovery," in Proceedings of the SPE Asia Pacific Enhanced Oil Recovery Conference, EORC 2015, pp. 222-238, mys, August 2015.

[93] L. Hendraningrat, S. Li, and O. Torsæter, "A coreflood investigation of nanofluid enhanced oil recovery," Journal of Petroleum Science and Engineering, vol. 111, pp. 128-138, 2013.

[94] L. Hendraningrat and O. Torsæter, "Metal oxide-based nanoparticles: revealing their potential to enhance oil recovery in different wettability systems," Applied Nanoscience, vol. 5, no. 2, pp. 181-199, 2014.

[95] O. A. Alomair, K. M. Matar, and Y. H. Alsaeed, "Nanofluids application for heavy oil recovery," in Proceedings of the SPE Asia Pacific Oil and Gas Conference and Exhibition - Changing the Game: Opportunities, Challenges and Solutions, APOGCE 2014, pp. 1346-1363, aus, October 2014.

[96] B. A. Suleimanov, F. S. Ismailov, and E. F. Veliyev, "Nanofluid for enhanced oil recovery," Journal of Petroleum Science and Engineering, vol. 78, no. 2, pp. 431-437, 2011.

[97] P. M. Mcelfresh, M. Wood, and D. Ector, "Stabilizing Nano Particle Dispersions in High Salinity, High Temperature Downhole Environments," in Proceedings of the SPE International Oilfield Nanotechnology Conference and Exhibition, Noordwijk, The Netherlands. 

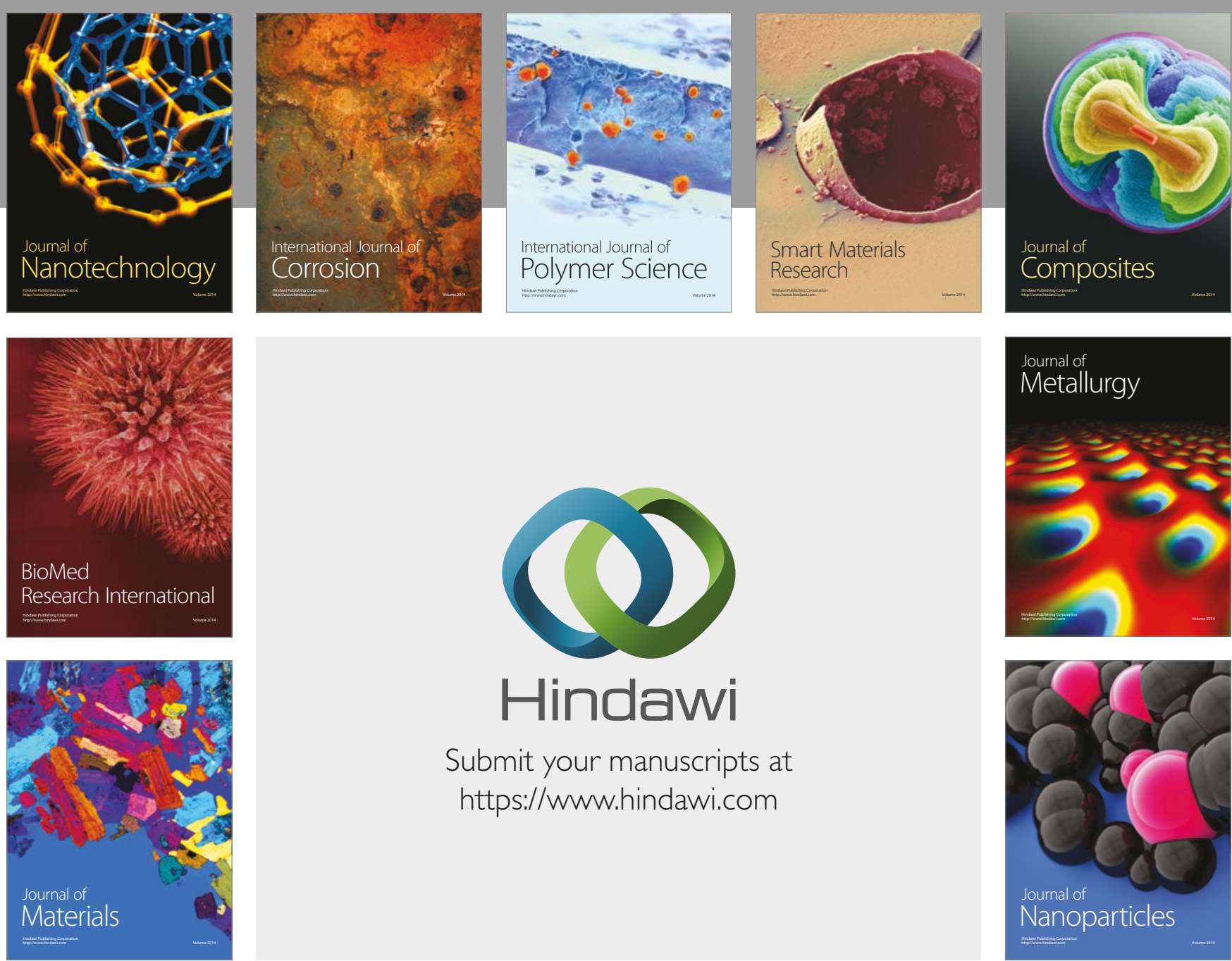

\section{Hindawi}

Submit your manuscripts at

https://www.hindawi.com
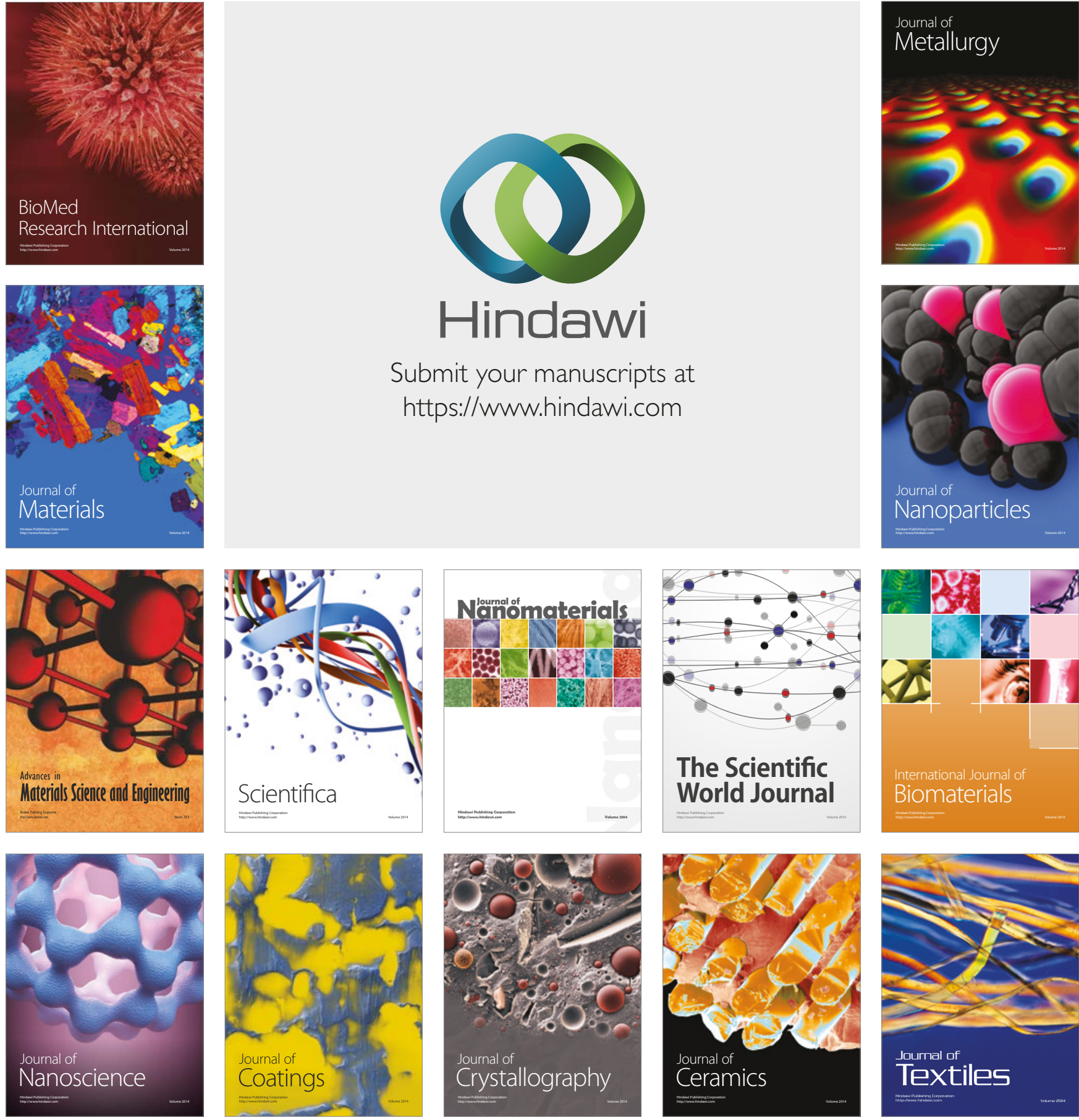

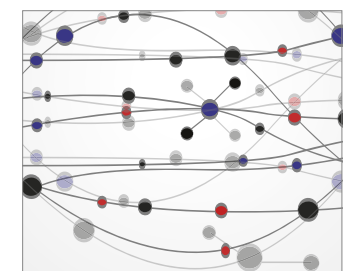

The Scientific World Journal
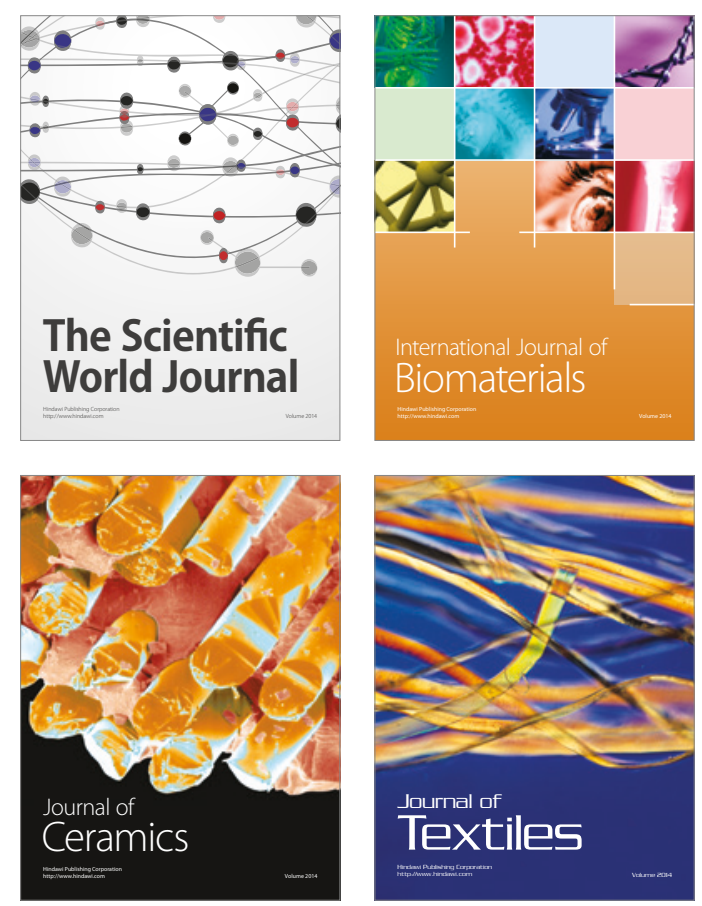